\title{
Evaluation of cardiovascular disease risk factors among diabetic patients with hypertension in Messelata region, Libya
}

\begin{abstract}
Background: Type 2 diabetes mellitus (T2DM) patients generally carry several risk factors for cardiovascular disease (CVD), including hyperglycemia, abnormal lipid profiles, as well as other 'nontraditional' risk factors, many of which may be closely associated with insulin resistance. Diabetes increases the risk of hypertension (HTN), due to its negative action on the arteries, which predisposes the narrowing of them and leads to hypertension. Hypertension is a strong risk factor for atherosclerotic cardiovascular disease, heart failure, and microvascular complications.
\end{abstract}

Objectives: This study aims to evaluate the risk factors for cardiovascular disease in T2DM patients with and without hypertension in the Messelata region.

Materials and methods: This study included 240 diabetics with and without high blood pressure and 120 healthy subjects of both sexes (60 males and 60 females in all groups), attending the Messelata Central Hospital. The participants blood pressure was measured in all groups, and age, gender were recorded for all study subjects. $5 \mathrm{ml}$ of venous blood was drawn to measure the levels of glucose (FBS), hemoglobin (HbAlc), and total cholesterol (TC), triglycerides (TG), HDL-C, LDL-C, and VLDL.

Results: The body mass index (BMI) $>25 \mathrm{~kg} / \mathrm{m}^{2}$ was $83.3 \%$ of females and males with diabetes, $80 \%, 91.8 \%$ of females and males with diabetes and hypertension. Family history of diabetes was $78.3 \%, 76.7 \%$, and $40 \%$ of female patients with diabetes, and females and males diabetes and hypertension, respectively. Serum LDL levels were abnormal in $46.7 \%, 41.7 \%, 33.3 \%, 20 \%$ of diabetic $+\mathrm{HTN}$ females, diabetic females, diabetic males, and diabetic $+\mathrm{HTN}$ males, respectively. Serum HDL levels were abnormal in $65 \%, 55 \%, 51 \%$, and $36.7 \%$ of diabetic + HTN males and females, diabetic males, and diabetic females, respectively. Serum cholesterol levels were abnormal in $30 \%$, $23.3 \%, 8.3 \%$, and $5 \%$ of diabetic + HTN females, diabetic females, diabetic males, and diabetic $+\mathrm{HTN}$ males respectively. In addition, serum triglycerides were abnormal in $55 \%, 41 \%, 36.7 \%$, and $35 \%$ of diabetic $+\mathrm{HTN}$ females, diabetic males and females, and diabetic + HTN males, respectively. Serum total cholesterol concentration and low-density lipoprotein concentration
Volume 7 Issue I - 2020

\author{
Azab Elsayed Azab,' Mohamed Omar \\ Albasha, ${ }^{2}$ Abdelsalam M Mansour ${ }^{3}$ \\ 'Faculty of Medicine, Sabratha University, Libya \\ ${ }^{2}$ Faculty of Science, Zawia University, Libya \\ ${ }^{3}$ Division of Genetic Engineering, Academy of Graduate Studies \\ Tripoli, Libya
}

Correspondence: Azab Elsayed Azab, Head of Physiology Department, Faculty of Medicine, Sabratha University, Libya, Tel 002180925674752,Email azabelsayed@yahoo.com

Received: March 19, 2020 | Published: April 24, 2020

were a significant $(\mathrm{P}<0.01)$ increase in males and females diabetic patients compared with controls. Serum total cholesterol, triglycerides, LDL, and VLDL concentrations were significantly $(\mathrm{P}<0.01)$ increased in females diabetic $+\mathrm{HTN}$, compared with control females. The present study showed that HDL concentration was significantly $(\mathrm{P}<0.01)$ decreased in males diabetic+HTN compared with control females.

Conclusion: It can be concluded that the results showed significant changes in most of the parameters in diabetic patients with and without hypertension compared to healthy subjects. Most of these changes were more pronounced in diabetics with hypertension patients than diabetic patients only. Therefore, Diabetic and hypertensive patients need measurement of blood pressure and lipid profile at regular intervals throughout their primary health care to prevent CVD and stroke. All patients with T2DM patients with and without hypertension must be started on primary prevention by health education, aggressive lifestyle changes, such as weight reduction and physical exercise to reduce the risk of coronary heart disease and atherosclerosis.

Keywords: cardiovascular diseases risk factors, dyslipidemia, lipids profile, diabetes mellitus, hypertension, Messelata region, Libya
Abbreviations: T2DM, Type 2 diabetes mellitus; DM, diabetes mellitus; BMI, body mass index; CVD, cardiovascular disease; HPLC, high performance liquid chromatography; LDL-C, low-density lipoprotein cholesterol; CETP, cholesteryl ester transfer protein; FBS, fasting blood sugar

\section{Introduction}

Type 2 diabetes mellitus (T2DM) is now a common and serious global health problem associated with older age, obesity, family history of diabetes, physical inactivity, other unhealthy lifestyle and behavioral patterns., ${ }^{1,2}$ Diabetes mellitus (DM) and its complications are the major and growing public health problem around the world, involvement in a developing country like Libya. ${ }^{3}$ Satti et al., ${ }^{4}$ reported that the incidence of diabetes is increasing at an alarming rate, with a predicted worldwide incidence of more than 640 million people by
2040. The Middle East occupies the second region after North America with the highest diabetes prevalence rates $(9.3 \%)$, and this number is expected to double in $<20$ years. ${ }^{2,5}$ However, the Libyan national non-communicable diseases survey in 2009 reported a prevalence of diabetes of $16.4 \% .{ }^{5,6}$ Lack of awareness and poor access to quality care increase diabetes-related complications such as heart attack, stroke and features of autonomic dysfunction. ${ }^{2,7,8}$ Diabetes mellitus is always associated with raised triglycerides. Hypertriglyceridemia is one of the risk factors in coronary artery disease. ${ }^{9,10} \mathrm{~T} 2 \mathrm{DM}$ patients generally carry several risk factors for CVD, including hyperglycemia, abnormal lipid profiles, alterations in inflammatory mediators and coagulation/ thrombolytic parameters, as well as other 'nontraditional' risk factors, many of which may be closely associated with insulin resistance. ${ }^{11}$ CVD is the most common cause of death in people with diabetes. It has been found that the presence of diabetes significantly increases the risk (two- to four folds) for developing CVD. ${ }^{12}$ Diabetes increases 
the risk of hypertension, due to its negative action on the arteries, which predisposes the narrowing of them and leads to hypertension. ${ }^{13}$ Adults with diabetes have a $77 \%-87 \%$ prevalence of hypertension, a $74 \%-81 \%$ prevalence of elevated low-density lipoprotein cholesterol (LDL-C), and a $62 \%-67 \%$ prevalence of obesity. ${ }^{14}$ Ahmida et al., ${ }^{3}$ reported that the high prevalence of lipid disorders in Libyan T2DM in Benghazi city suggests that they might be playing a major role in the development of atherosclerosis in Libyan patients.

Hypertension is common among patients with diabetes, with the prevalence depending on type and duration of diabetes, age, sex, race/ ethnicity, body mass index (BMI), history of glycemic control, and the presence of kidney disease, among other factors. ${ }^{15-18}$ Furthermore, hypertension is a strong risk factor for atherosclerotic cardiovascular disease (CVD), heart failure, and microvascular complications. ${ }^{18}$ Hypertension accelerates and worsens the harmful effects of diabetes on the arteries, so those who suffer from both diseases tend to suffer more frequently from myocardial infarction, thrombosis and other complications. ${ }^{13}$ In developing countries, hypertension is on the rise due to the increase in urbanization and the adoption of western lifestyles. ${ }^{19,20}$ Hypertension has been termed 'silent killer' a chronic illness with adverse effects principally involving the central nervous system, the retina, the heart and the kidneys. ${ }^{20,21}$ It afflicts more than one billion population worldwide and is a leading cause of morbidity and mortality. ${ }^{21}$ Considering that the great relevance of diabetes mellitus in Libya has been attributed to reduced mortality related to hypertension and other cardiovascular causes, greater attention must be given to the health care delivered to hypertensive patients, to minimize the risks and profile of morbimortality among them. In addition, to our knowledge, the evidence reporting the cardiovascular risk factors in type II diabetic patients with and without hypertension in Libya is very few. Therefore, the present study aimed to evaluate the lipids profile parameters in T2DM patients with and without hypertension in the Messelata region.

\section{Subjects and methods}

\section{Study design and population}

A cross-sectional study was conducted among 240 participants, type 2 diabetes mellitus with hypertension and type 2 diabetes mellitus patients without hypertension (each included 120 patients) and 120 participants with normal BP (normotensives) and non-diabetic, attending central hospital of Messelata for a routine health check-up in the period over six months from the $1^{\text {st }}$ of January 2018 to $30^{\text {th }}$ of June 2018. To eliminate the effects of age and gender on the comparison between cases and control groups, age and gender were selected in each pair of groups as similar as possible. All the participants were residents of surrounding areas in Messelata and aged between 30-70 years. Ethical approvals and patients consent statements were taken from everyone; data were collected through face-to-face interviews, using a structured questionnaire. Demographic and anthropometric data were included age, gender. Blood pressure (systolic and diastolic) measurements were done for the participants using the auscultator technique, which involves the use of a mercury sphygmomanometer by a trained health professional. All patients and normal participants were free from chronic degenerative diseases such as cancer or peritonitis. Patients fulfilling one of the following criteria were defined as being hypertensive: systolic blood pressure $\geq 140 \mathrm{mmHg}$, diastolic blood pressure $\geq 90 \mathrm{mmHg}$, or use of antihypertensive medication irrespective of blood pressure. Diabetes mellitus was defined as a fasting glucose level of $\geq 126 \mathrm{mg} / \mathrm{dL}$ or the use of hypoglycemic agents.

\section{Samples and biochemical analysis}

A volume of $3 \mathrm{~mL}$ of venous blood was collected in the morning after an overnight fast (12-14 hours), in fluoride (grey) and EDTA containing (lavender) vacutainers. The grey capped ones were used for estimation of fasting glucose and the lavender capped ones were used for estimation of HbA1C. Glucose levels were determined using the Hexokinase method, using commercial kit from Meril Diagnostics in AutoQuant 400i auto analyser. HbA1C levels were measured in GluQuant A1C using ion exchange high performance liquid chromatography (HPLC) method. Also, $3 \mathrm{ml}$ of venous blood was collected in a plain vials for biochemical tests. After clotting of blood in the plain vial, serum was separated, within an hour; by centrifugation at $3000-5000 \mathrm{~g}$ for 5 minutes. Serum was used for measurements of the levels of serum cholesterol, TG, HDL-C, and LDL-C. Biochemical studies were performed using commercially available kits from Biomeriux (France), and serum parameters were quantified according to the manufacturer's instructions. Cholesterol was determined after enzymatic hydrolysis and oxidation according to the method described by Richmond. ${ }^{22}$ Triglycerides were determined according to the method described by Carr et al., ${ }^{23}$ LDL Cholesterol test results are based on a reading of light reflected off a test strip that has changed color after blood is applied. The intensity of the color is directly proportional to the concentration of LDL cholesterol in the sample. The analyzer converts this reading into a LDL cholesterol result and displays it. This test, which selectively measures LDL cholesterol, is an enzymatic colorimetric test based on the "Trinder Method" for the determination of cholesterol. In the presence of oxygen, cholesterol is oxidized by cholesterol oxidase to cholesterol-4-en-one and hydrogen peroxide. In the presence of peroxidase, hydrogen peroxide reacts with 4-aminoantipyrine and N, N disubstituted aniline to form a blue dye. ${ }^{24}$ Phossphotungstic acid and magnesium ions selectively precipitating all lipoproteins except the HDL fraction-cholesterol present in the supernatant can be determined by the same method used for total cholesterol. ${ }^{25}$

\section{Ethical considerations}

Ethical approvals were obtained from the ethical committee of Libyan Academy of Science, and Messelata Central Hospital as a point for sample collection and analysis. Informed consent was taken from all the participants before their inclusion in this study.

\section{Statistical analysis}

Results were expressed as mean \pm SE. Data were analyzed by independent t-test, chi-square fisher exact test using the SPSS for Windows, version 25 . The differences between mean \pm SD were tested at $P<0.05$. In all statistical tests, the probability level of $P<0.05$ was considered significant.

\section{Results}

This study included 240 participants, 120 of them with type 2 diabetes mellitus patients without hypertension, 120 with type 2 diabetes mellitus with hypertension and 120 participants with normal BP and non-diabetic. All the participants were aged between 30-70 years. The mean ages of all patients groups were showed a non significant changes, where, control males, control females, diabetic males, diabetic females, and diabetic $+\mathrm{HTN}$ males and females patients 
were $\quad(56.90 \pm 1.10), \quad(53.50 \pm 1.03), \quad(57.70 \pm 2.30), \quad(53.00 \pm 1.59)$, $(58.10 \pm 2.40)$, and $(56.60 \pm 1.68)$ years, respectively.

\section{Distribution of patients according to age more than $\mathbf{5 0}$ years and BMI more than $25 \mathrm{Kg} / \mathrm{m} 2$}

The subjects of age more than 50 years were 45 subjects $(75 \%)$ in males diabetic patients, 51 subjects $(85 \%)$ in males diabetic + HTN patients, 43 subjects $(71.7 \%)$ in females diabetic patients, and 47 subjects $(78.3 \%)$ in females diabetic+HTN patients (Table 1). The subjects of body mass index more than $25 \mathrm{Kg} / \mathrm{m}^{2}$ were 50 subjects $(83.3 \%)$ in males diabetic patients, 48 subjects $(80 \%)$ in males diabetic+HTN patients, 50 subjects $(83.3 \%)$ in females diabetic patients, and 55 subjects $(91.7 \%)$ in females diabetic+HTN patients (Table 1).

Table I Distribution of patients according to age more than 50 years and BMI more than $25 \mathrm{Kg} / \mathrm{m}^{2}$

\begin{tabular}{lllll}
\hline Parameters & Age $(>\mathbf{5 0}$ years $)$ & BMI $\left(>\mathbf{2 5} \mathbf{~ K g} / \mathbf{m}^{2}\right)$ \\
Groups & Frequency & $\%$ & Frequency & $\%$ \\
\hline Males Diabetic & 45 & 75 & 50 & 83.3 \\
Males (Diabetic+HTN) & 51 & 85 & 48 & 80 \\
Females Diabetic & 43 & 71.7 & 50 & 83.3 \\
Females (Diabetic+HTN) & 47 & 78.3 & 55 & 91.7 \\
\hline
\end{tabular}

\section{Distribution of patients according to family history of diabetes}

Family history can play always an important role in developing any medical disease including that of diabetes and hypertension. In this study 2 subjects $(3.7 \%), 24$ subjects $(40 \%), 47$ subjects $(78.3 \%)$, and 46 subjects $(76.7 \%)$ in males diabetic, males diabetic+HTN, females diabetic, and females diabetic + HTN patients, respectively were showed a history of diabetes in their families (Table 2).

Table 2 Distribution of patients according to family history of diabetes

\begin{tabular}{lll}
\hline Parameter & \multicolumn{2}{l}{ Family History } \\
Groups & Frequency & $\%$ \\
\hline Males Diabetic & 2 & 3.7 \\
Males (Diabetic+HTN) & 24 & 40 \\
Females Diabetic & 47 & 78.3 \\
Females (Diabetic+HTN) & 46 & 76.7 \\
\hline
\end{tabular}

\section{Distribution of patients according to abnormal levels} of HbAlc

The abnormal levels of HbAlc (7.5-9\%) were 22 subjects (36.7\%) in males diabetic patients, 42 subjects $(70 \%)$ in males diabetic $+\mathrm{HTN}$ patients, 16 subjects $(26.7 \%)$ in females diabetic patients, and 22 subjects $(36.7 \%)$ in females diabetic + HTN patients. But, the abnormal levels of HbAlc (>9\%) were 26 subjects $(43.3 \%)$ in males diabetic, 20 subjects $(33.3 \%)$ in males diabetic + HTN, 22 subjects $(36.7 \%)$ in females diabetic and diabetic + HTN patients (Table $3 \&$ Figure 1).

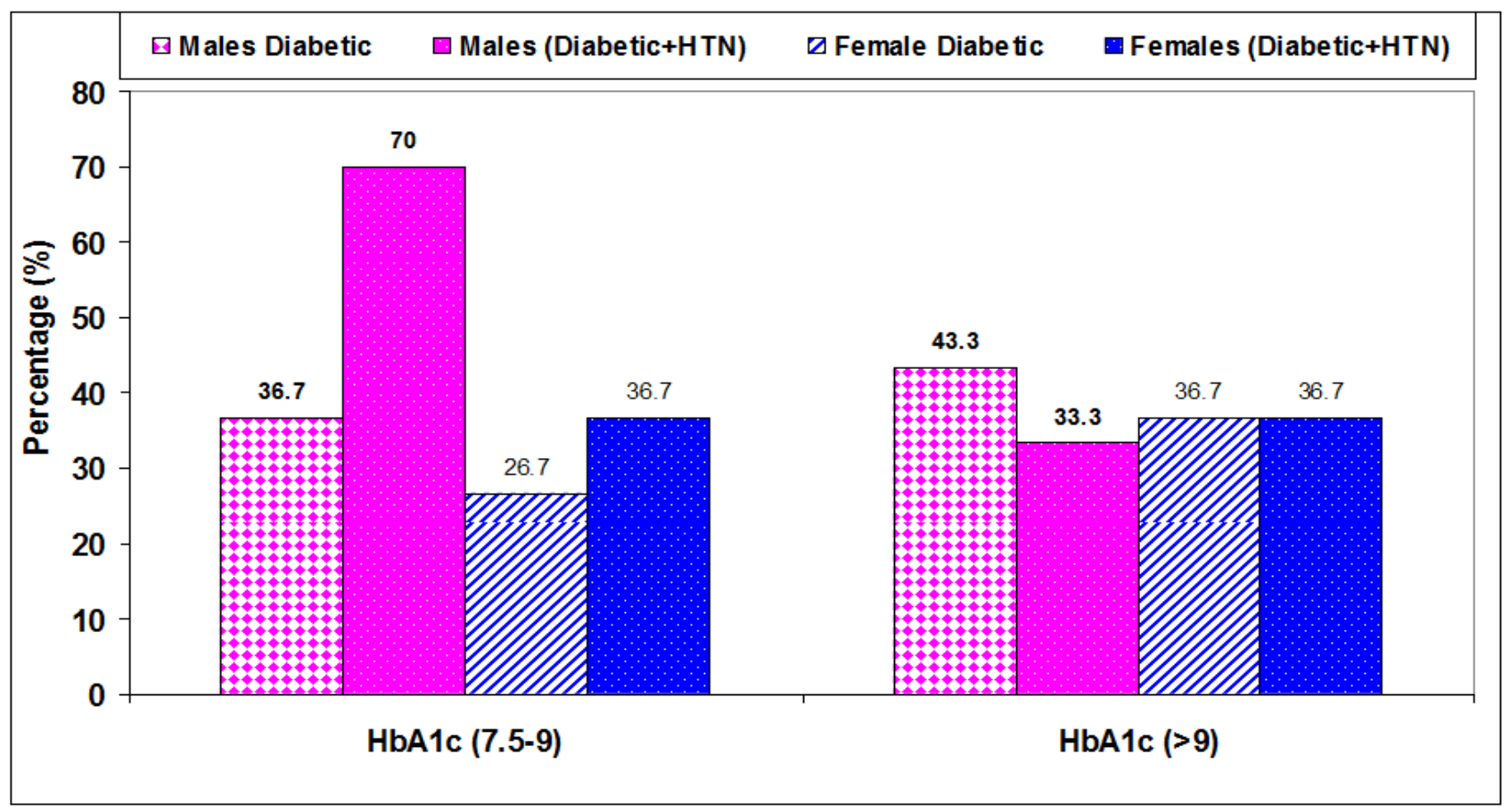

Figure I Distribution of patients according to abnormal levels of HbAlc. 
Table 3 Distribution of patients according to abnormal levels of HbAlc

\begin{tabular}{lllll}
\hline Parameters & HbAlc (7.5-9) $(\%)$ & HbAlc (>9) (\%) \\
Groups & Frequency & $\%$ & Frequency & $\%$ \\
\hline Males Diabetic & 22 & 36.7 & 26 & 43.3 \\
Males (Diabetic+HTN) & 42 & 70 & 20 & 33.3 \\
Females Diabetic & 16 & 26.7 & 22 & 36.7 \\
Females (Diabetic+HTN) & 22 & 36.7 & 22 & 36.7 \\
\hline
\end{tabular}

Distribution of patients according to disturbance in lipids profile

Results in Table (4) \& Figure (2) shows the distribution of patients according to disturbance in lipids profile. Serum LDL levels were abnormal in $46.7 \%, 41.7 \%, 33.3 \%, 20 \%$ of diabetic $+\mathrm{HTN}$ females, diabetic females, diabetic males, and diabetic $+\mathrm{HTN}$ males respectively. Serum HDL levels were abnormal in $65 \%, 55 \%, 51 \%$, and $36.7 \%$ of diabetic + HTN males and females, diabetic males, and diabetic females, respectively. Serum cholesterol levels were abnormal in $30 \%, 23.3 \%, 8.3 \%$, and $5 \%$ of diabetic + HTN females, diabetic females, diabetic males, and diabetic $+\mathrm{HTN}$ males respectively. In addition, serum triglycerides were abnormal in 55\%, 41\%, 36.7\%, and $35 \%$ of diabetic + HTN females, diabetic males and females, and diabetic + HTN males, respectively.

Table 4 Distribution of patients according to disturbance in lipids profile

\begin{tabular}{|c|c|c|c|c|c|c|c|c|}
\hline \multirow[t]{2}{*}{ Parameters } & \multicolumn{2}{|c|}{$\begin{array}{l}\text { LDL } \\
(>100 \mathrm{mg} / \mathrm{dl})\end{array}$} & \multicolumn{2}{|l|}{$\begin{array}{l}\text { HDL } \\
(<40 \mathrm{mg} / \mathrm{dl})\end{array}$} & \multicolumn{2}{|l|}{$\begin{array}{l}\text { Cholesterol } \\
(>200 \mathrm{mg} / \mathrm{dl})\end{array}$} & \multicolumn{2}{|c|}{$\begin{array}{l}\text { Triglycerides } \\
\text { (>I50mg/dl) }\end{array}$} \\
\hline & Frequency & $\%$ & Frequency & $\%$ & Frequency & $\%$ & Frequency & $\%$ \\
\hline Males Diabetic & 20 & 33.3 & 31 & 51.7 & 5 & 8.3 & 25 & 41.7 \\
\hline Males (Diabetic+HTN) & 12 & 20 & 39 & 65 & 3 & 5 & 21 & 35 \\
\hline Females Diabetic & 25 & 41.7 & 22 & 36.7 & 14 & 23.3 & 22 & 36.7 \\
\hline Females (Diabetic+HTN) & 28 & 46.7 & 33 & 55 & 18 & 30 & 33 & 55 \\
\hline
\end{tabular}

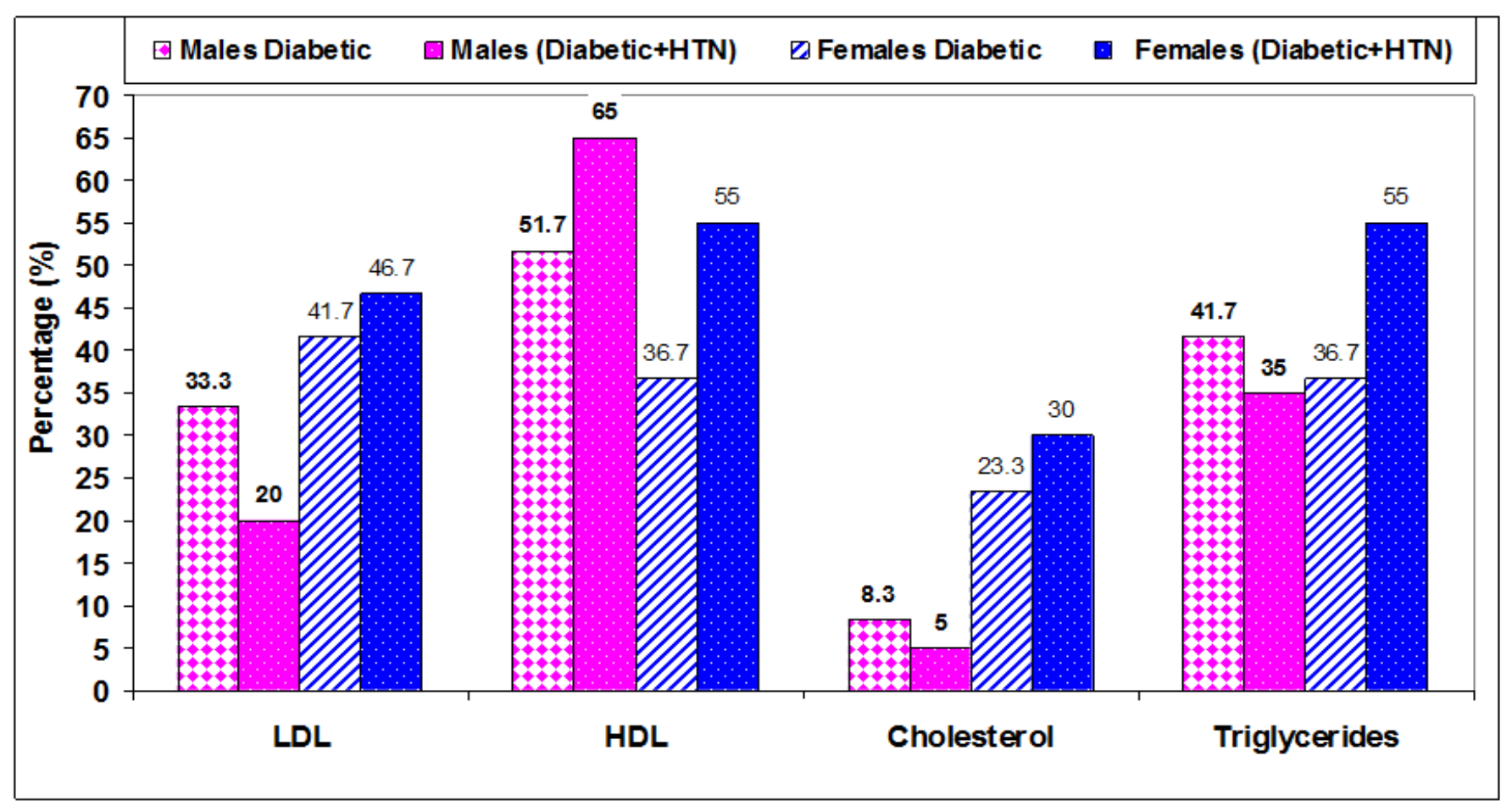

Figure 2 Distribution of patients according to disturbance in lipids profile.

Weight, BMI, systolic and diastolic blood pressure in control and diabetic patients

Data shown in Table (5) \& Figure (3) indicated a significant $(P<0.05)$ increase in body weight $(\mathrm{Kg})$ of diabetic males $(77.60 \pm 2.00)$ compared with control males $(71.90 \pm 1.00)$, and a significant $(P<0.01)$ increase in diabetic female $(80.60 \pm 2.99)$ compared with control females $(68.30 \pm 0.84)$. Body mass index $\left(\mathrm{Kg} / \mathrm{m}^{2}\right)$ was significantly $(P<0.01)$ increased in males and females diabetic $(27.50 \pm 0.60),(30.70 \pm 1.16)$

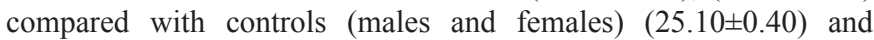




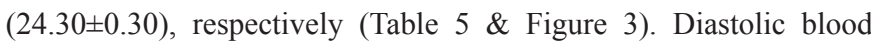
pressure $(\mathrm{mm} \mathrm{Hg})$ was significantly $(P<0.01)$ increased in males diabetic (81.50 \pm 0.70$)$ compared with control males $(78.90 \pm 0.60)$. Systolic blood pressure in males and females diabetic showed nonsignificant changes compared to controls (Table 5 \& Figure 3 ).

\section{Comparison of fasting blood sugar (FBS) concentration and $\mathrm{HbAl}$ c between control and diabetic patients}

Fasting blood sugar had a significant $(P<0.01)$ increase in males diabetic $(274.20 \pm 17.20)$, females diabetic $(218.00 \pm 14.40)$ compared with controls (males \& females) $(86.40 \pm 1.50),(83.20 \pm 1.87)$, respectively, (Table $6 \&$ Figure 4). HbA1c had a significant $(P<0.01)$ increase in males diabetic $(9.00 \pm 0.30)$, females diabetic $(8.40 \pm 0.36)$ compared with controls (males \& females) $(5.20 \pm 0.10),(6.00 \pm 0.14)$ respectively (Table $6 \&$ Figure 5).

\section{Comparison of serum lipid profile parameters concentrations between control and diabetic patients}

The present study showed that total cholesterol concentration $(\mathrm{mg} / \mathrm{dl})$ was a significant $(P<0.01)$ increase in males diabetic

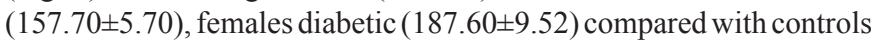

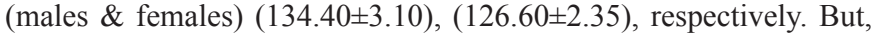
there were non-significant changes recorded in serum triglycerides and VLDL concentrations $(\mathrm{mg} / \mathrm{dl})$ in males and females diabetic patients compared to controls (Table $7 \&$ Figure 6). The present study showed that HDL concentration $(\mathrm{mg} / \mathrm{dl})$ was a significant $(P<0.01)$ increase in females diabetic $(46.80 \pm 2.20)$ compared with control females (39.60 \pm 0.34$)$ (Table $7 \&$ Figure 6). Low-density lipoprotein concentration $(\mathrm{mg} / \mathrm{dl})$ was a significantly $(P<0.01)$ increased in males diabetic (88.10 \pm 4.50$)$, females diabetic $(98.40 \pm 4.55)$ compared with controls (males \& females) (67.70 \pm 2.90$),(63.00 \pm 2.47)$, respectively (Table $7 \&$ Figure 6).

Table 5 Weight, BMI, systolic and diastolic blood pressure in control and diabetic patients

\begin{tabular}{llll}
\hline $\begin{array}{l}\text { Groups } \\
\text { Parameters }\end{array}$ & & $\begin{array}{l}\text { Control } \\
\text { Mean } \pm \text { SE }\end{array}$ & $\begin{array}{l}\text { Diabetic Patients } \\
\text { Mean } \pm \text { SE }\end{array}$ \\
\hline Weight $(\mathrm{Kg})$ & Males & $71.90 \pm 1.00$ & $77.60 \pm 2.00^{*}$ \\
& Females & $68.30 \pm 0.84$ & $80.60 \pm 2.99 * *$ \\
Body Mass Index (BMI) $\left(\mathrm{Kg} / \mathrm{m}^{2}\right)$ & Males & $25.10 \pm 0.40$ & $27.50 \pm 0.60^{* *}$ \\
& Females & $24.30 \pm 0.30$ & $30.70 \pm 1.16^{* *}$ \\
Systolic Blood Pressure $(\mathrm{mm} \mathrm{Hg})$ & Males & $121.60 \pm 0.40$ & $121.70 \pm 0.80$ \\
& Females & $120.80 \pm 0.24$ & $120.50 \pm 0.94$ \\
Diastolic Blood Pressure $(\mathrm{mm} \mathrm{Hg})$ & Males & $78.90 \pm 0.60$ & $81.50 \pm 0.70^{* *}$ \\
& Females & $78.40 \pm 0.48$ & $78.80 \pm 0.89$
\end{tabular}

*: Significant differences as compared with the control group $(P<0.05)$

**: Significant differences as compared with the control group $(\mathrm{P}<0.0 \mathrm{I})$

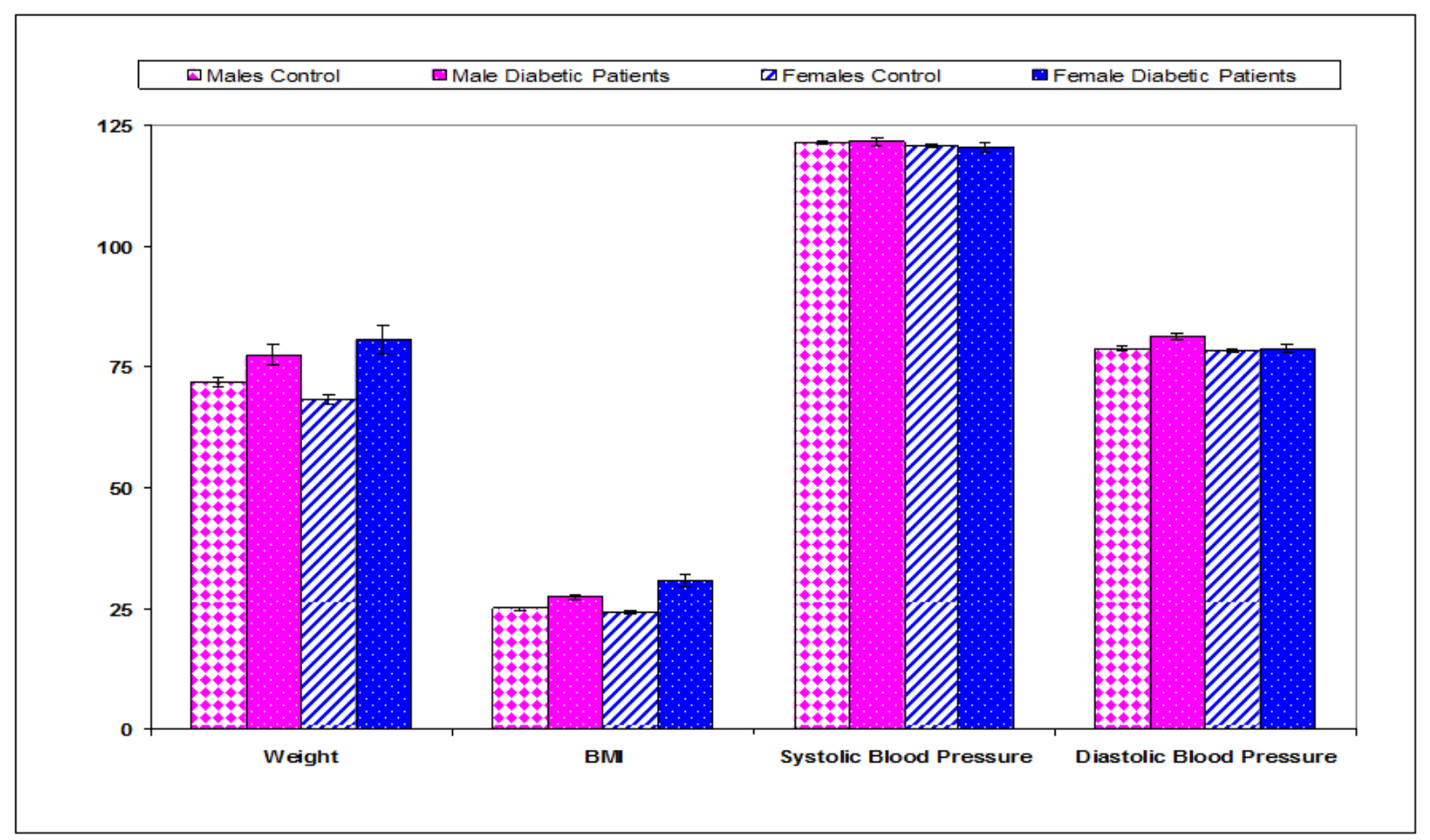

Figure 3 Weight, BMI, systolic and diastolic blood pressure in control and diabetic patients.

Citation: Azab AE, Albasha MO, Mansour AM. Evaluation of cardiovascular disease risk factors among diabetic patients with hypertension in Messelata region, Libya.J Diabetes Metab Disorder Control. 2020;7(I):14-29. DOI: 10.15406/jdmdc.2020.07.00195 


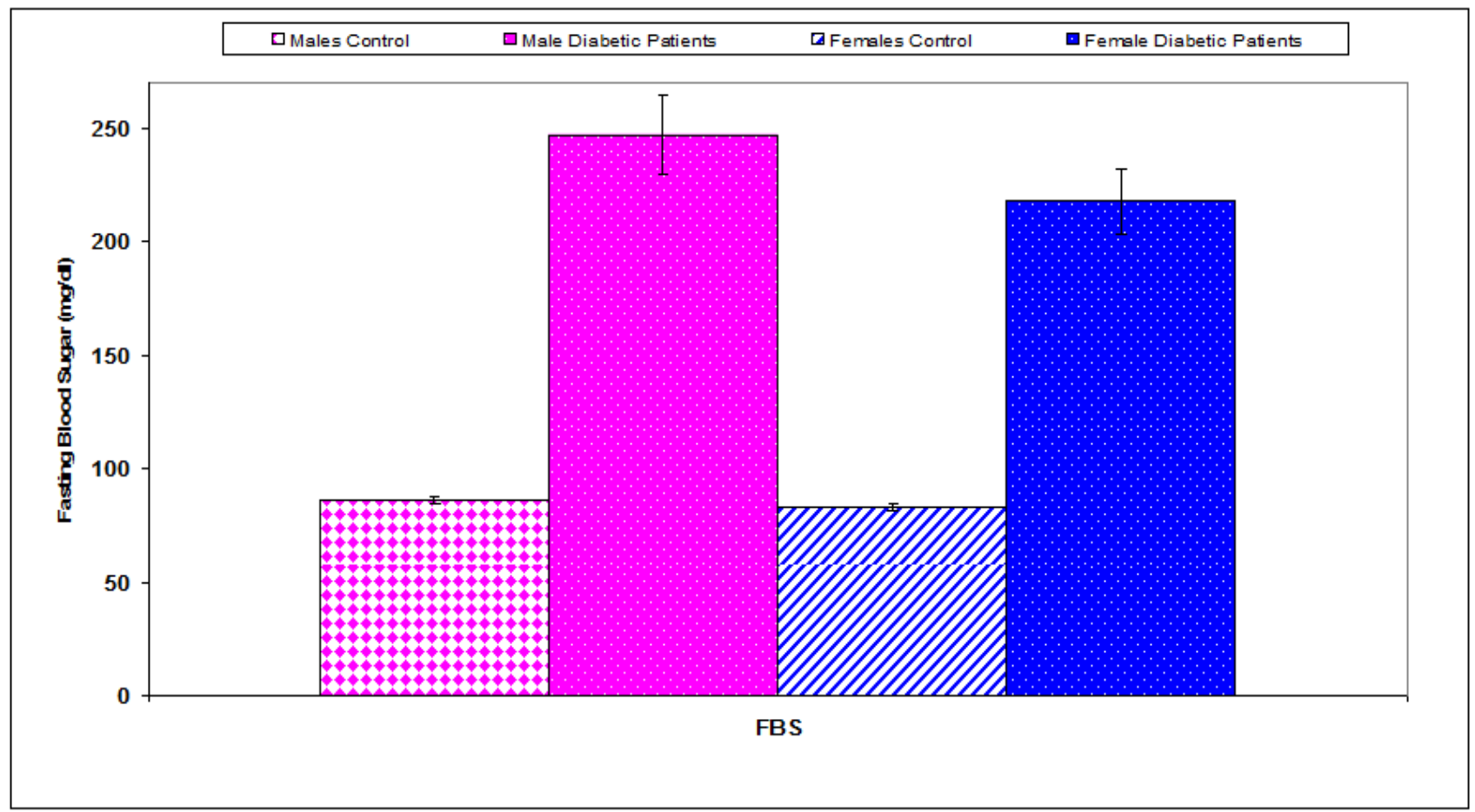

Figure 4 Comparison of fasting blood sugar (FBS) concentration between control and diabetic patients.

Table 6 Comparison of fasting blood sugar (FBS) concentration and Hemoglobin Alc between control and diabetic patients

\begin{tabular}{llll}
\hline $\begin{array}{l}\text { Groups } \\
\text { Parameters }\end{array}$ & $\begin{array}{l}\text { Control } \\
\text { Mean } \pm \text { SE }\end{array}$ & $\begin{array}{l}\text { Diabetic Patients } \\
\text { Mean } \pm \text { SE }\end{array}$ \\
\hline Fasting blood sugar concentration $(\mathrm{mg} / \mathrm{dl})$ & Males & $86.40 \pm 1.50$ & $274.20 \pm 17.20 * *$ \\
& Females & $83.20 \pm 1.87$ & $218.00 \pm 14.40 * *$ \\
Hemoglobin Alc (HbAlc) (\%) & Males & $5.20 \pm 0.10$ & $9.00 \pm 0.30 * *$ \\
& Females & $6.00 \pm 0.14$ & $8.40 \pm 0.36 * *$ \\
\hline
\end{tabular}

**: Significant differences as compared with the control group $(\mathrm{P}<0.0 \mathrm{I})$

Table 7 Comparison of serum lipid profile parameters concentrations between control and diabetic patients

\begin{tabular}{llll}
\hline $\begin{array}{l}\text { Groups } \\
\text { Parameters }\end{array}$ & $\begin{array}{l}\text { Control } \\
\text { Mean } \pm \text { SE }\end{array}$ & $\begin{array}{l}\text { Diabetic Patients } \\
\text { Mean } \pm \text { SE }\end{array}$ \\
\hline Total cholesterol (TC) concentration (mg/dl) & Males & $134.40 \pm 3.10$ & $157.70 \pm 5.70^{* *}$ \\
& Females & $126.60 \pm 2.35$ & $187.60 \pm 9.52^{* *}$ \\
Triglycerides (Trig) concentration (mg/dl) & Males & $139.50 \pm 8.20$ & $147.60 \pm 13.50$ \\
High Density Lipids (HDL) concentration (mg/dl) & Females & $120.40 \pm 2.31$ & $211.80 \pm 51.00$ \\
& Males & $38.80 \pm 0.80$ & $40.10 \pm 1.20$ \\
Low Density Lipids (LDL) concentration (mg/d) & Females & $39.60 \pm 0.34$ & $46.80 \pm 2.20^{* *}$ \\
& Males & $67.70 \pm 2.90$ & $88.10 \pm 4.50^{* *}$ \\
Very Low Density lipids (VLDL) concentration (mg/dl) & Females & $63.00 \pm 2.47$ & $98.40 \pm 4.55^{* *}$ \\
& Males & $27.90 \pm 1.60$ & $29.50 \pm 2.70$ \\
\hline
\end{tabular}

**: Significant differences as compared with the control group $(\mathrm{P}<0.0 \mathrm{I})$ 


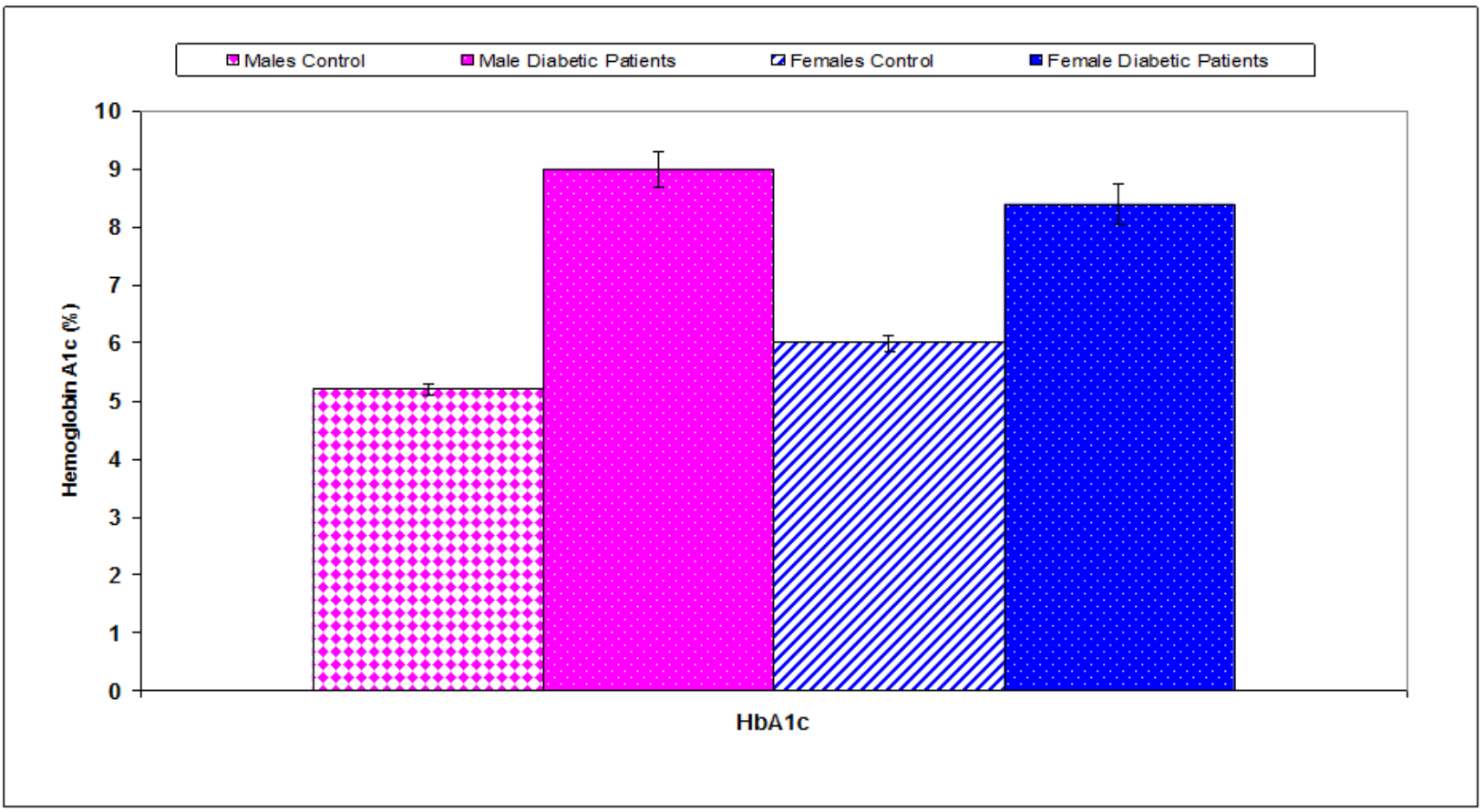

Figure 5 Comparison of Hemoglobin Alc between control and diabetic patients.

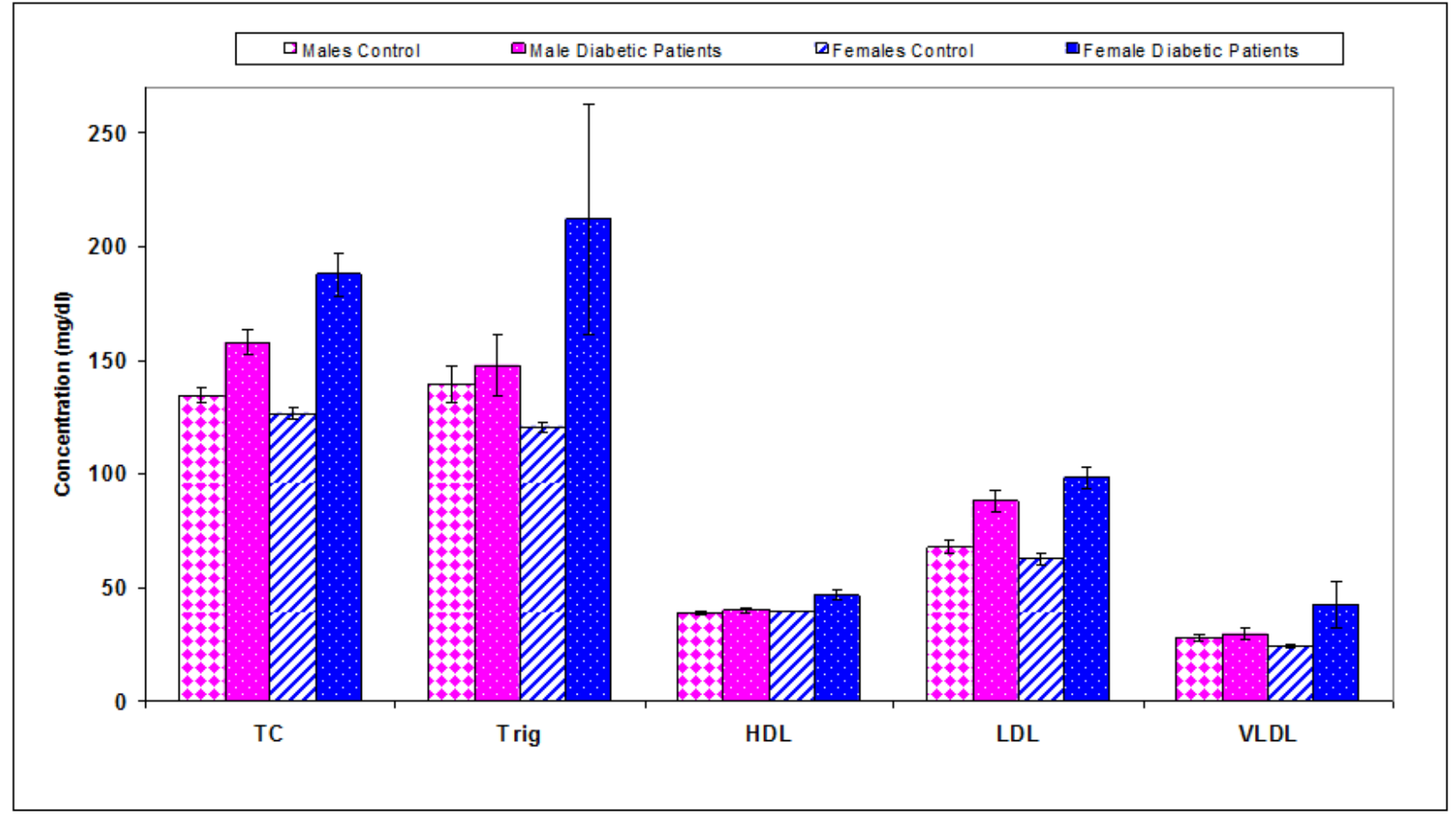

Figure 6 Comparison of serum lipid profile parameters concentrations between control and diabetic patients.

Weight, BMI, systolic and diastolic blood pressure in control and diabetic+HTN patients

Data shown in Table (8) \& Figure (7) indicated a significant $(P<0.05)$ increase in body weight $(\mathrm{Kg})$ of females diabetic $+\mathrm{HTN}$ patients $(81.50 \pm 2.31)$ compared with control females $(68.30 \pm 0.84)$, and a significant $(P<0.01)$ increase in males diabetic + HTN patients

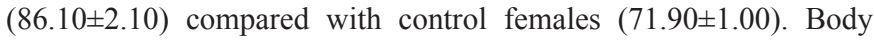
mass index $\left(\mathrm{Kg} / \mathrm{m}^{2}\right)$ was significantly $(P<0.01)$ increased in males and females diabetic + HTN patients $(29.70 \pm 1.00),(34.50 \pm 1.51)$ compared with controls (males and females) $(25.10 \pm 0.40)$ and (24.30 \pm 0.30$)$, 
respectively (Table $8 \&$ Figure 7$)$. Systolic blood pressure $(\mathrm{mm}$ $\mathrm{Hg})$ was significantly $(P<0.01)$ increased in males and females diabetic + HTN patients $(149.20 \pm 3.00)$ and $(136.50 \pm 4.93)$ compared

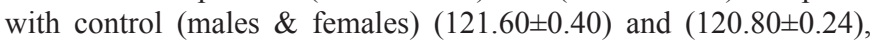
respectively (Table 8 \& Figure 7). Diastolic blood pressure (mm Hg) was significantly $(P<0.01)$ increased in males and females diabetic + HTN patients $(87.00 \pm 1.00)$ and $(86.70 \pm 1.48)$ compared with control (males \& females) $(81.50 \pm 0.70)$ and $(78.40 \pm 0.48)$, respectively (Table 8 \& Figure 7).

Table 8 Weight, BMI, systolic and diastolic blood pressure in control and diabetic+HTN patients

\begin{tabular}{llll}
\hline Groups & & Control & Diabetic + HTN (Patients) \\
Parameters & & Mean \pm SE & Mean \pm SE \\
\hline Weight $(\mathrm{Kg})$ & Males & $71.90 \pm 1.00$ & $86.10 \pm 2.10^{* *}$ \\
& Females & $68.30 \pm 0.84$ & $81.50 \pm 2.31 *$ \\
Body Mass Index $(\mathrm{BMI})\left(\mathrm{Kg} / \mathrm{m}^{2}\right)$ & Males & $25.10 \pm 0.40$ & $29.70 \pm 1.00^{* *}$ \\
& Females & $24.30 \pm 0.30$ & $34.50 \pm 1.51^{* *}$ \\
Systolic Blood Pressure $(\mathrm{mm} \mathrm{Hg})$ & Males & $121.60 \pm 0.40$ & $149.20 \pm 3.00^{* *}$ \\
& Females & $120.80 \pm 0.24$ & $136.50 \pm 4.93 * *$ \\
Diastolic Blood Pressure $(\mathrm{mm} \mathrm{Hg})$ & Males & $81.50 \pm 0.70$ & $87.00 \pm 1.00^{* * *}$ \\
& Females & $78.40 \pm 0.48$ & $86.70 \pm 1.48 * *$ \\
\hline
\end{tabular}

*: Significant differences as compared with the control group $(P<0.05)$;

**: Significant differences as compared with the control group $(\mathrm{P}<0.0 \mathrm{I})$.

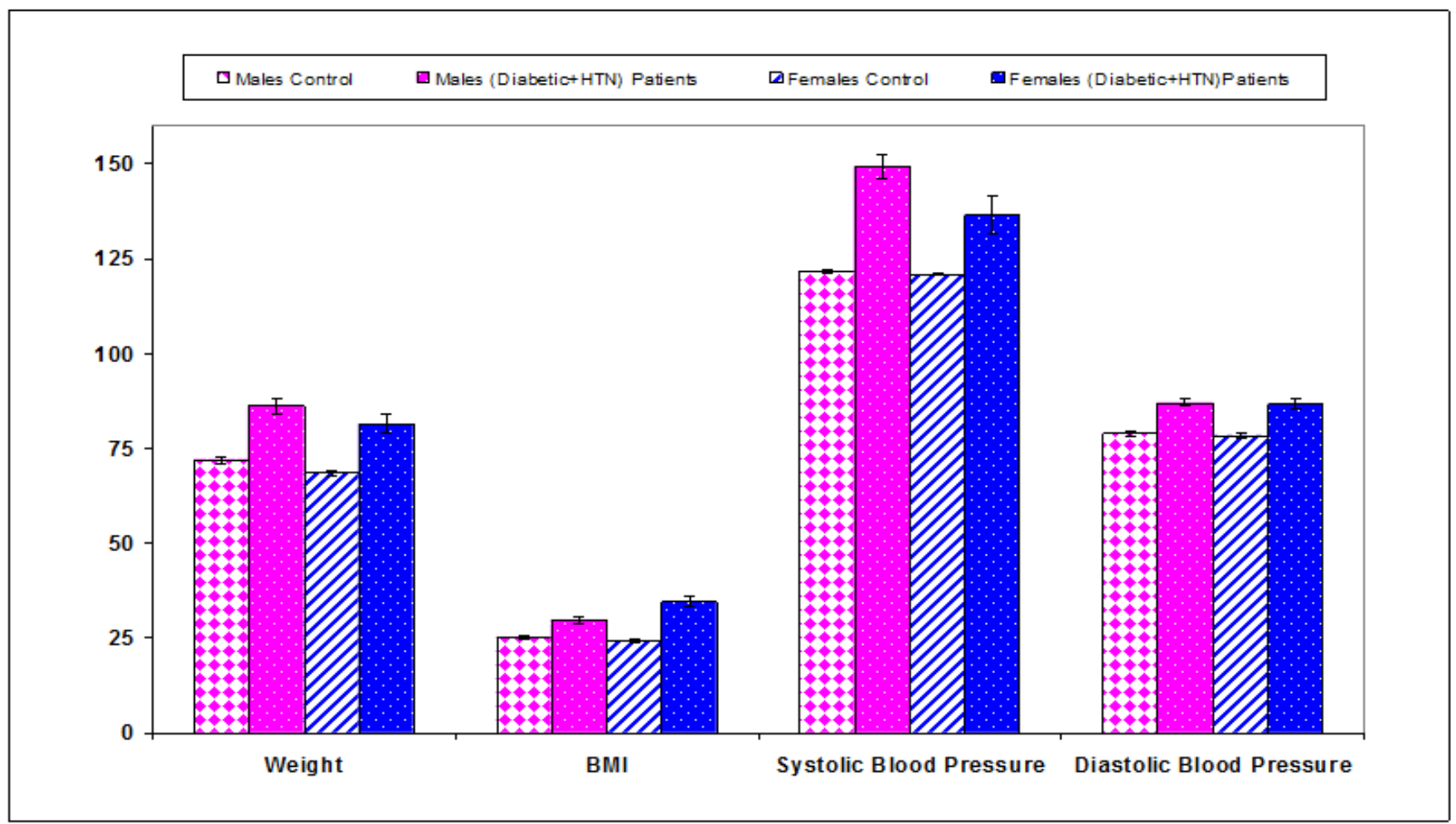

Figure 7 Weight, BMI, systolic, and diastolic blood pressure in control and diabetic $+\mathrm{HTN}$ patients. 
Comparison of fasting blood sugar (FBS) and Hemoglobin Alc between control and diabetic+HTN patients

Fasting blood sugar concentration had a significant $(P<0.01)$ increase in males diabetic + HTN patients $(214.40 \pm 12.10)$, females diabetic + HTN patients $(203.40 \pm 19.24)$ compared with controls (males\& females) $(86.40 \pm 1.50),(83.20 \pm 1.87)$, respectively, (Table 9 \& Figure 8). Hemoglobin A1c had a significant $(P<0.01)$ increase in males diabetic + HTN patients $(9.00 \pm 0.20)$, females diabetic + HTN patients $(8.60 \pm 0.27)$ compared with controls (males \& females) (5.20 \pm 0.10$),(6.00 \pm 0.14)$ respectively (Table $9 \&$ Figure 9$)$.

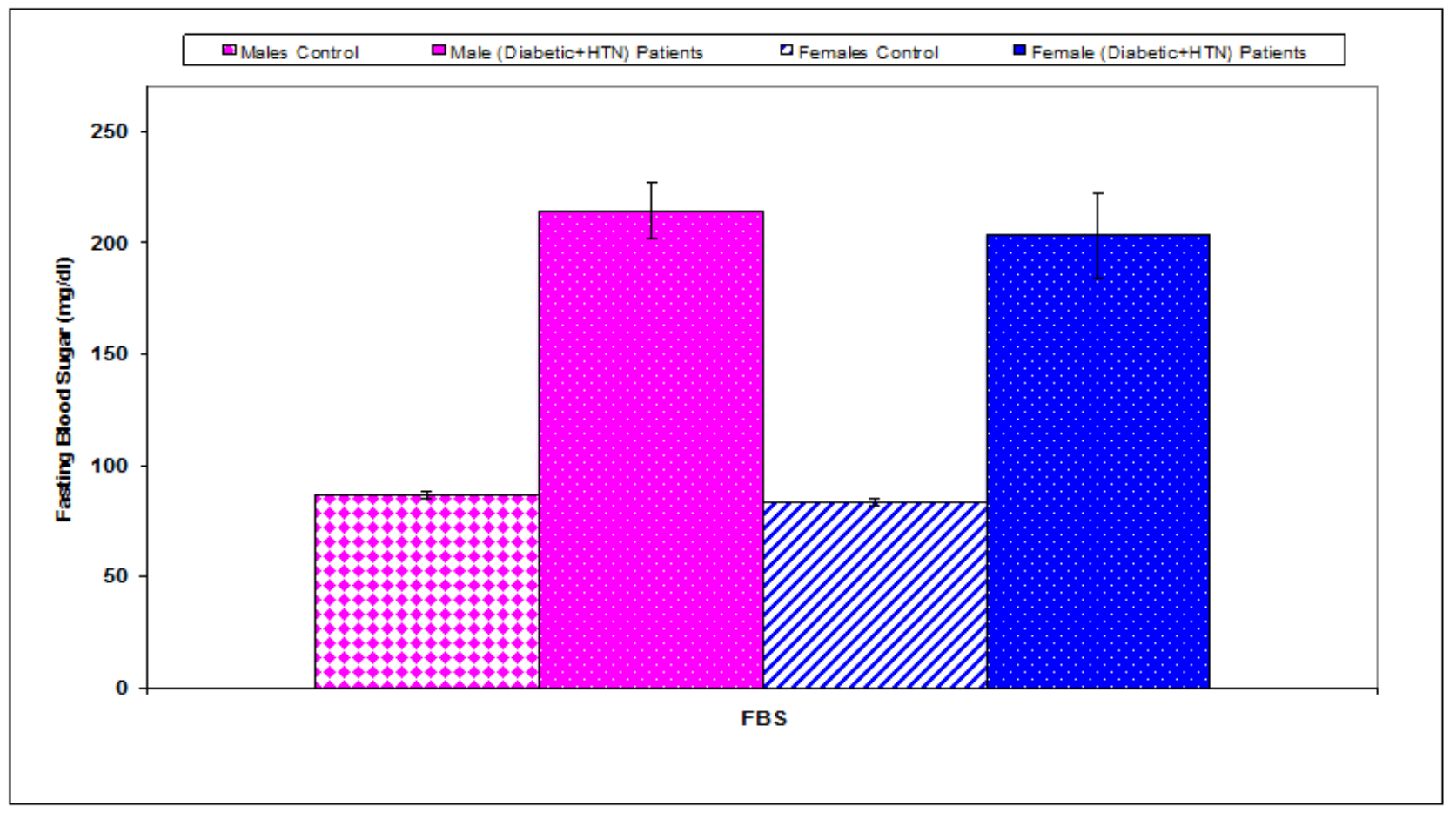

Figure 8 Comparison of fasting blood sugar (FBS) concentration between control and diabetic+HTN patients.

Table 9 Comparison of fasting blood sugar (FBS) concentration and Hemoglobin Alc between control and diabetic + HTN patients

\begin{tabular}{llll}
\hline $\begin{array}{ll}\text { Groups } \\
\text { Parameters }\end{array}$ & $\begin{array}{l}\text { Control } \\
\text { Mean } \pm \text { SE }\end{array}$ & $\begin{array}{l}\text { Diabetic + HTN Patients } \\
\text { Mean } \pm \text { SE }\end{array}$ \\
\hline Fasting blood sugar concentration $(\mathrm{mg} / \mathrm{d})$ & & $86.40 \pm 1.50$ & $214.40 \pm 12.10^{* *}$ \\
& Males & $83.20 \pm 1.87$ & $203.40 \pm 19.24^{* *}$ \\
Hemoglobin Alc (HbAlc) (\%) & Females & $5.20 \pm 0.10$ & $9.00 \pm 0.20^{* *}$ \\
& Males & $6.00 \pm 0.14$ & $8.60 \pm 0.27^{* *}$ \\
\hline
\end{tabular}

**: Significant differences as compared with the control group $(\mathrm{P}<0.0 \mathrm{I})$

Comparison of serum lipid profile parameters concentrations between control and diabetic+HTN patients

The present study showed that serum total cholesterol, triglycerides, LDL, and VLDL concentrations $(\mathrm{mg} / \mathrm{dl})$ were significantly $(P<0.01)$ increased in females diabetic + HTN $(170.5 \pm 6.08)$, $(181.9 \pm 16.60),(92.3 \pm 6.66)$, and $(36.4 \pm 3.32)$ compared with control females $(126.6 \pm 2.35),(120.4 \pm 2.31),(63.0 \pm 2.47)$, and $(24.1 \pm 0.46)$ respectively. But, there were non-significant changes recorded in serum total cholesterol, triglycerides, LDL, and VLDL concentrations in males diabetic + HTN patients compared to controls (Table 10 \& Figure 10).
The present study showed that HDL concentration $(\mathrm{mg} / \mathrm{dl})$ was significantly $(P<0.01)$ decreased in males diabetic + HTN $(34.9 \pm 1.6)$ compared with control females (38.8 \pm 0.8$)$ (Table 10 \& Figure 10).

\section{Weight, BMI, systolic and diastolic blood pressure in diabetic patients and diabetic+HTN patients}

Data are shown in Table 4 \& Figure 4 indicated a significant $(P<0.01)$ increase in body weight $(\mathrm{Kg})$ of males diabetic $+\mathrm{HTN}$ patients (86.1 \pm 2.1$)$ compared with males diabetic patients $(68.30 \pm 0.84)$ (Table 11 \& Figure 11). Body mass index $\left(\mathrm{Kg} / \mathrm{m}^{2}\right)$ in males and females diabetic + HTN patients were non significantly changed compared with diabetic (males and females) (Table 11 \& Figure 11). Systolic blood pressure $(\mathrm{mm} \mathrm{Hg})$ was significantly $(P<0.01)$ 
increased in males and females diabetic + HTN patients $(149.2 \pm 3.0)$ and (136.5 \pm 4.93$)$ compared with diabetic (males \& females) $(121.7 \pm 0.8)$ and $(120.5 \pm 0.94)$, respectively (Table $11 \&$ Figure 11$)$. Diastolic Systolic blood pressure $(\mathrm{mm} \mathrm{Hg})$ was significantly $(P<0.01)$ increased in males and females diabetic + HTN patients $(87.0 \pm 1.0)$ and (86.7 \pm 1.48$)$ compared with diabetic (males \& females) $(78.9 \pm 0.6)$ and (78.8 \pm 0.89$)$, respectively (Table $11 \&$ Figure 11$)$.

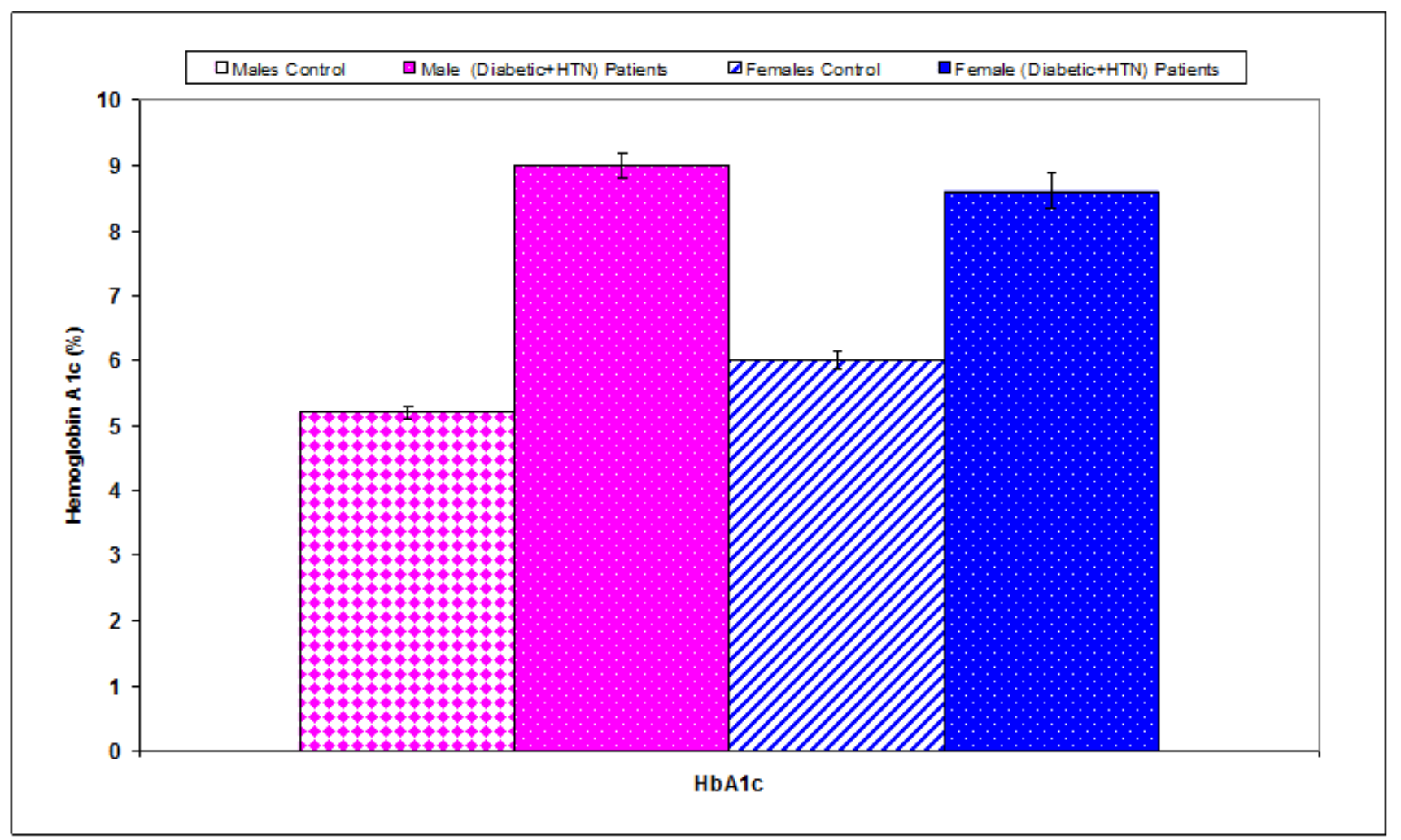

Figure 9 Comparison of Hemoglobin Alc between control and diabetic + HTN patients.

Comparison of fasting blood sugar (FBS) concentration and Hemoglobin Alc between diabetic patients and diabetic+HTN patients

Fasting blood sugar concentration had a significant $(P<0.01)$ increase in males diabetic + HTN patients $(214.4 \pm 12.1)$ compared with diabetic males (274.2 \pm 17.2$)$ (Table 4 \& Figure 4). Hemoglobin A1c had non significant changes in males and females diabetic + HTN patients compared with diabetic (males \& females) (Table 12 \& Figure 13).

Table 10 Comparison of serum lipid profile parameters between control and diabetic + HTN patients

\begin{tabular}{llll}
\hline $\begin{array}{l}\text { Groups } \\
\text { Parameters }\end{array}$ & & $\begin{array}{l}\text { Control } \\
\text { Mean } \pm \text { SE }\end{array}$ & $\begin{array}{l}\text { Diabetic+ HTN Patients } \\
\text { Mean } \pm \text { SE }\end{array}$ \\
\hline Total cholesterol (TC) concentration (mg/dl) & Males & $134.4 \pm 3.1$ & $132.9 \pm 7.2$ \\
Triglycerides (Trig) concentration (mg/dl) & Females & $126.6 \pm 2.35$ & $170.5 \pm 6.08^{* *}$ \\
& Males & $139.5 \pm 8.2$ & $133.5 \pm 12.6$ \\
High Density Lipids (HDL) concentration (mg/dl) & Females & $120.4 \pm 2.31$ & $181.9 \pm 16.60^{* *}$ \\
& Males & $38.8 \pm 0.8$ & $34.9 \pm 1.6 *$ \\
Low Density Lipids (LDL) concentration (mg/dl) & Females & $39.6 \pm 0.34$ & $41.9 \pm 1.73$ \\
& Males & $67.7 \pm 2.9$ & $71.4 \pm 5.5$ \\
Very Low Density lipids (VLDL) concentration (mg/d) & Females & $63.0 \pm 2.47$ & $92.3 \pm 6.66 * *$ \\
& Males & $27.9 \pm 1.6$ & $26.7 \pm 2.5$ \\
\hline
\end{tabular}

**: Significant differences as compared with the control group $(\mathrm{P}<0.0 \mathrm{I})$ 


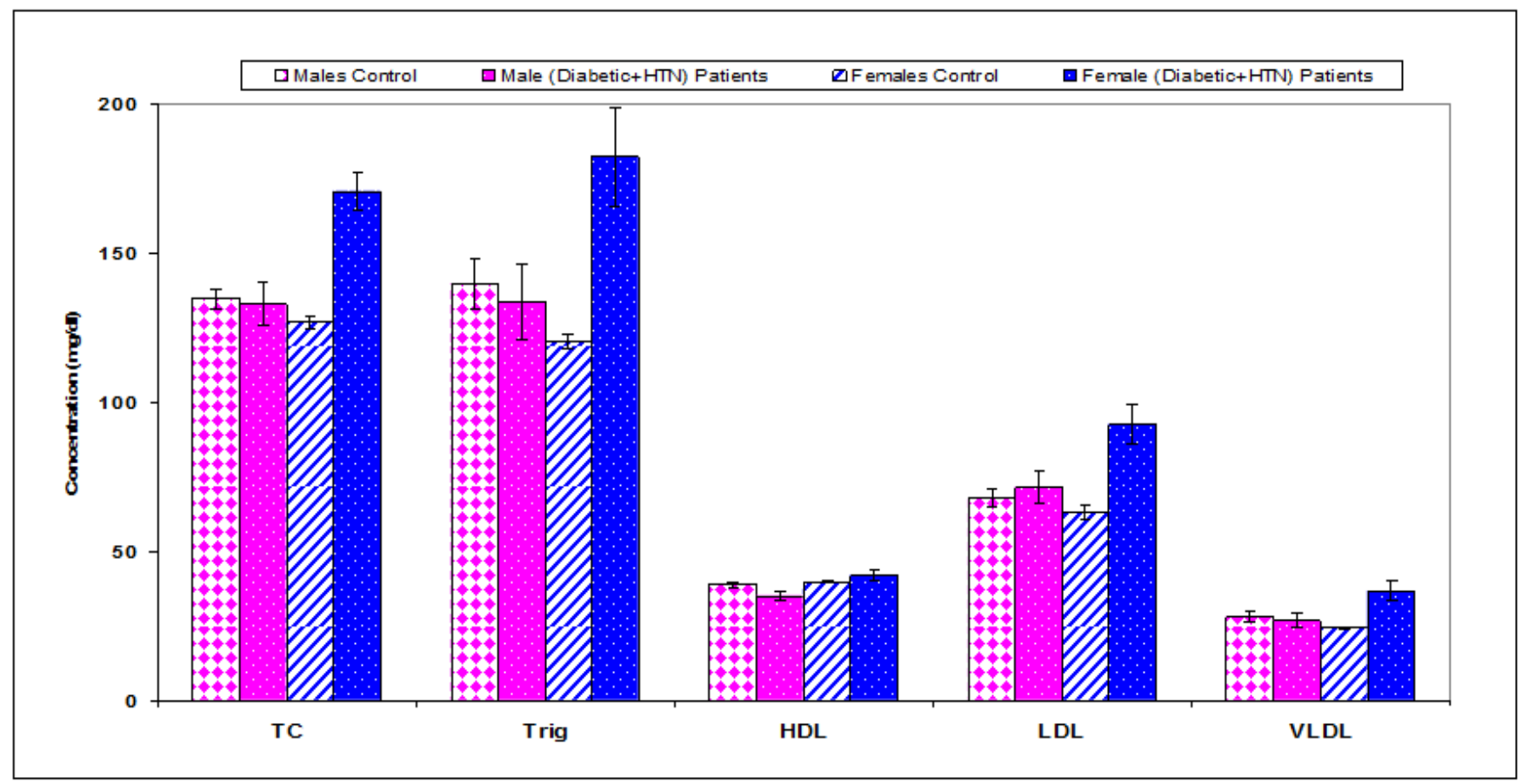

Figure 10 Comparison of serum lipid profile parameters between control and diabetic $+\mathrm{HTN}$ patients.

Table I I Weight, BMI, systolic and diastolic blood pressure in diabetic patients and diabetic + HTN patients

\begin{tabular}{llll}
\hline Groups & & Diabetic Patients & Diabetic+ HTN ( Patients) \\
Parameters & & Mean \pm SE & Mean \pm SE \\
\hline Weight $(\mathrm{Kg})$ & Males & $77.6 \pm 2.0$ & $86.1 \pm 2 . I^{* *}$ \\
& Females & $80.6 \pm 2.99$ & $81.5 \pm 2.31$ \\
Body Mass Index $(\mathrm{BMI})\left(\mathrm{Kg} / \mathrm{m}^{2}\right)$ & Males & $27.5 \pm 0.6$ & $29.7 \pm 1.0$ \\
& Females & $30.7 \pm 1.16$ & $34.5 \pm 1.51$ \\
Systolic Blood Pressure $(\mathrm{mm} \mathrm{Hg})$ & Males & $121.7 \pm 0.8$ & $149.2 \pm 3.0^{* *}$ \\
& Females & $120.5 \pm 0.94$ & $136.5 \pm 4.93^{* *}$ \\
Diastolic Blood Pressure $(\mathrm{mm} \mathrm{Hg})$ & Males & $78.9 \pm 0.6$ & $87.0 \pm 1.0^{* *}$ \\
& Females & $78.8 \pm 0.89$ & $86.7 \pm 1.48^{* *}$ \\
\hline
\end{tabular}

**: Significant differences as compared with diabetic patients group $(\mathrm{P}<0.0 \mathrm{I})$

Table 12 Comparison of fasting blood sugar (FBS) concentration and Hemoglobin Alc between diabetic patients and diabetic + HTN patients

\begin{tabular}{llll}
\hline Groups & & Diabetic Patients & Diabetic + HTN Patients \\
Parameters & & Mean \pm SE & Mean \pm SE \\
\hline Fasting blood sugar concentration $(\mathrm{mg} / \mathrm{dl})$ & Males & $274.2 \pm 17.2$ & $214.4 \pm 12 . \mathrm{I}^{* *}$ \\
& Females & $218.0 \pm 14.40$ & $203.4 \pm 19.24$ \\
Hemoglobin Alc (HbAlc) $(\%)$ & Males & $9.0 \pm 0.3$ & $9.0 \pm 0.2$
\end{tabular}

**: Significant differences as compared with diabetic patients group $(\mathrm{P}<0.0 \mathrm{I})$ 


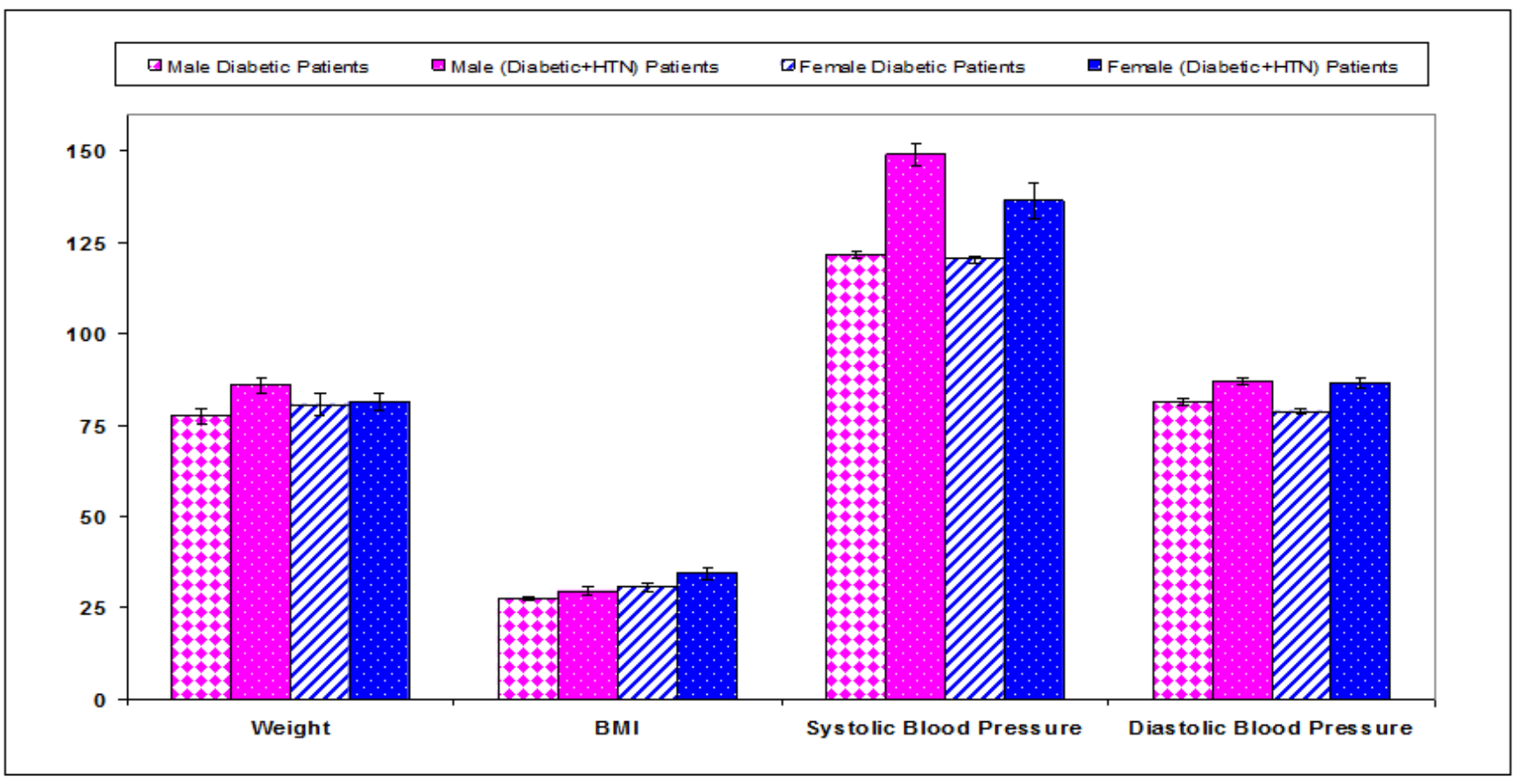

Figure I I Weight, BMI, systolic and diastolic blood pressure in diabetic patients and diabetic+HTN patients.

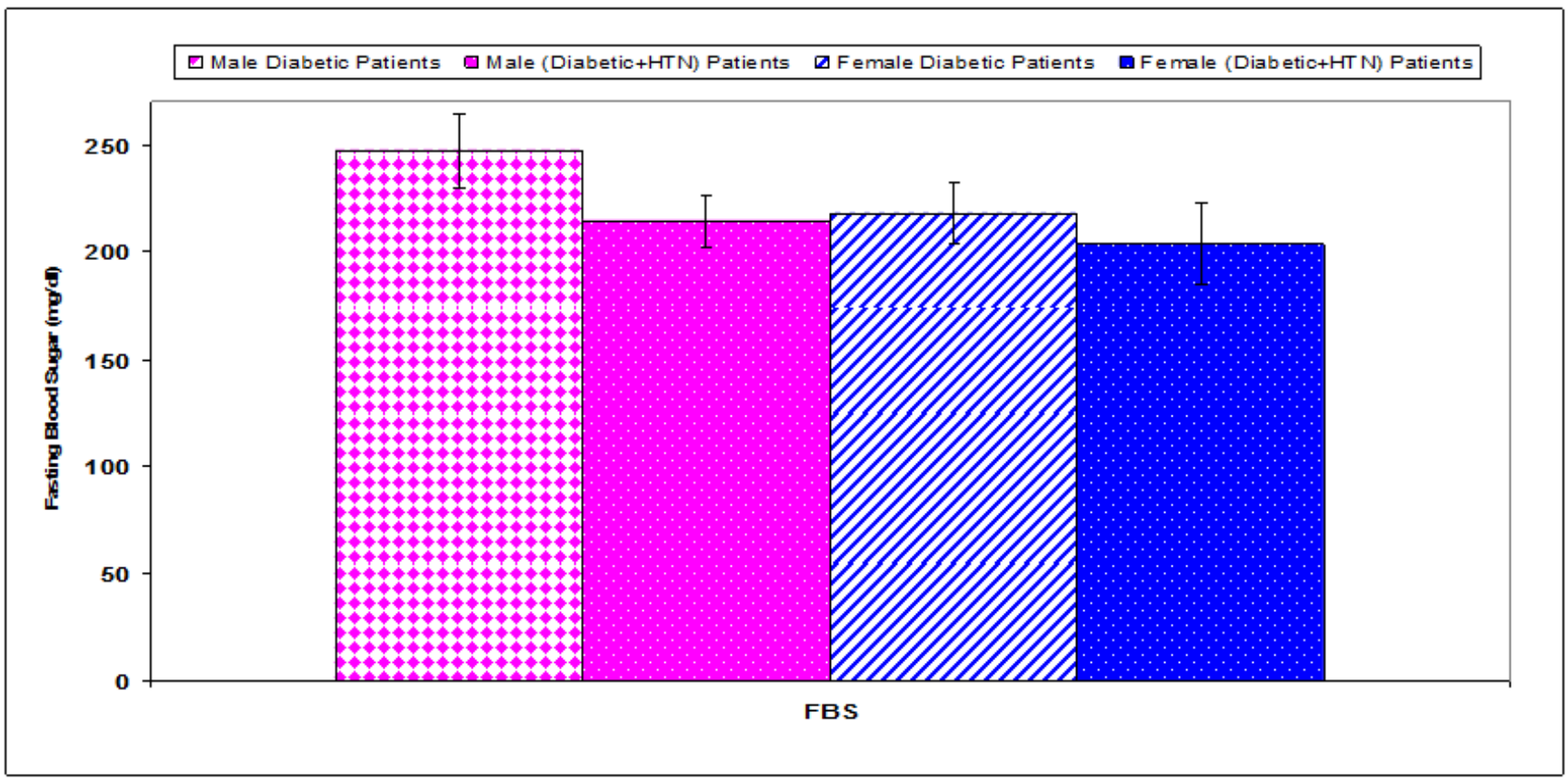

Figure 12 Comparison of fasting blood sugar (FBS) concentration between diabetic patients and diabetic $+\mathrm{HTN}$ patients.

Comparison of serum lipid profile parameters concentrations between diabetic patients and diabetic+HTN patients

Serum total cholesterol concentration $(\mathrm{mg} / \mathrm{dl})$ was significantly $(P<0.01)$ decreased in males diabetic + HTN patients $(132.9 \pm 7.2)$ compared with diabetic males (157.7 \pm 5.7$)$. But, there were non- significant changes recorded in serum total cholesterol, triglycerides, LDL, HDL, and VLDL concentrations in females diabetic+HTN patients compared to diabetic patients (Table 13 \& Figure 14). The present study showed that HDL and LDL concentrations ( $\mathrm{mg} / \mathrm{dl}$ ) was significantly $(P<0.05)$ decreased in males diabetic + HTN patients $(34.9 \pm 1.6)$ and $(71.4 \pm 5.5)$ compared with diabetic males $(40.1 \pm 1.2)$ and (88.1 \pm 4.5$)$, respectively (Table 13 \& Figure 14). 
Table I 3 Comparison of serum lipid profile parameters concentrations between diabetic patients and diabetic $+\mathrm{HTN}$ patients

\begin{tabular}{|c|c|c|c|}
\hline Groups & & Diabetic Patients & Diabetic + HTN Patients \\
\hline Parameters & & Mean \pm SE & Mean \pm SE \\
\hline \multirow[t]{2}{*}{ Total cholesterol (TC) concentration (mg/dl) } & Males & $157.7 \pm 5.7$ & $132.9 \pm 7.2^{* *}$ \\
\hline & Females & $187.6 \pm 9.52$ & $170.5 \pm 6.08$ \\
\hline \multirow[t]{2}{*}{ Triglycerides (Trig) concentration (mg/dl) } & Males & $147.6 \pm 13.5$ & $133.5 \pm 12.6$ \\
\hline & Females & $211.8 \pm 51.00$ & $181.9 \pm 16.60$ \\
\hline \multirow[t]{2}{*}{ High Density Lipids (HDL) concentration (mg/dl) } & Males & $40.1 \pm 1.2$ & $34.9 \pm 1.6^{*}$ \\
\hline & Females & $46.8 \pm 2.20$ & $41.9 \pm 1.73$ \\
\hline \multirow[t]{2}{*}{ Low Density Lipids (LDL) concentration (mg/dl) } & Males & $88.1 \pm 4.5$ & $71.4 \pm 5.5^{*}$ \\
\hline & Females & $98.4 \pm 4.55$ & $92.3 \pm 6.66$ \\
\hline \multirow[t]{2}{*}{ Very Low Density lipids (VLDL) concentration (mg/dl) } & Males & $29.5 \pm 2.7$ & $26.7 \pm 2.5$ \\
\hline & Females & $42.4 \pm 10.20$ & $36.4 \pm 3.32$ \\
\hline
\end{tabular}

*: Significant differences as compared with diabetic patients group $(\mathrm{P}<0.05)$.

**: Significant differences as compared with diabetic patients group $(\mathrm{P}<0.0 \mathrm{I})$

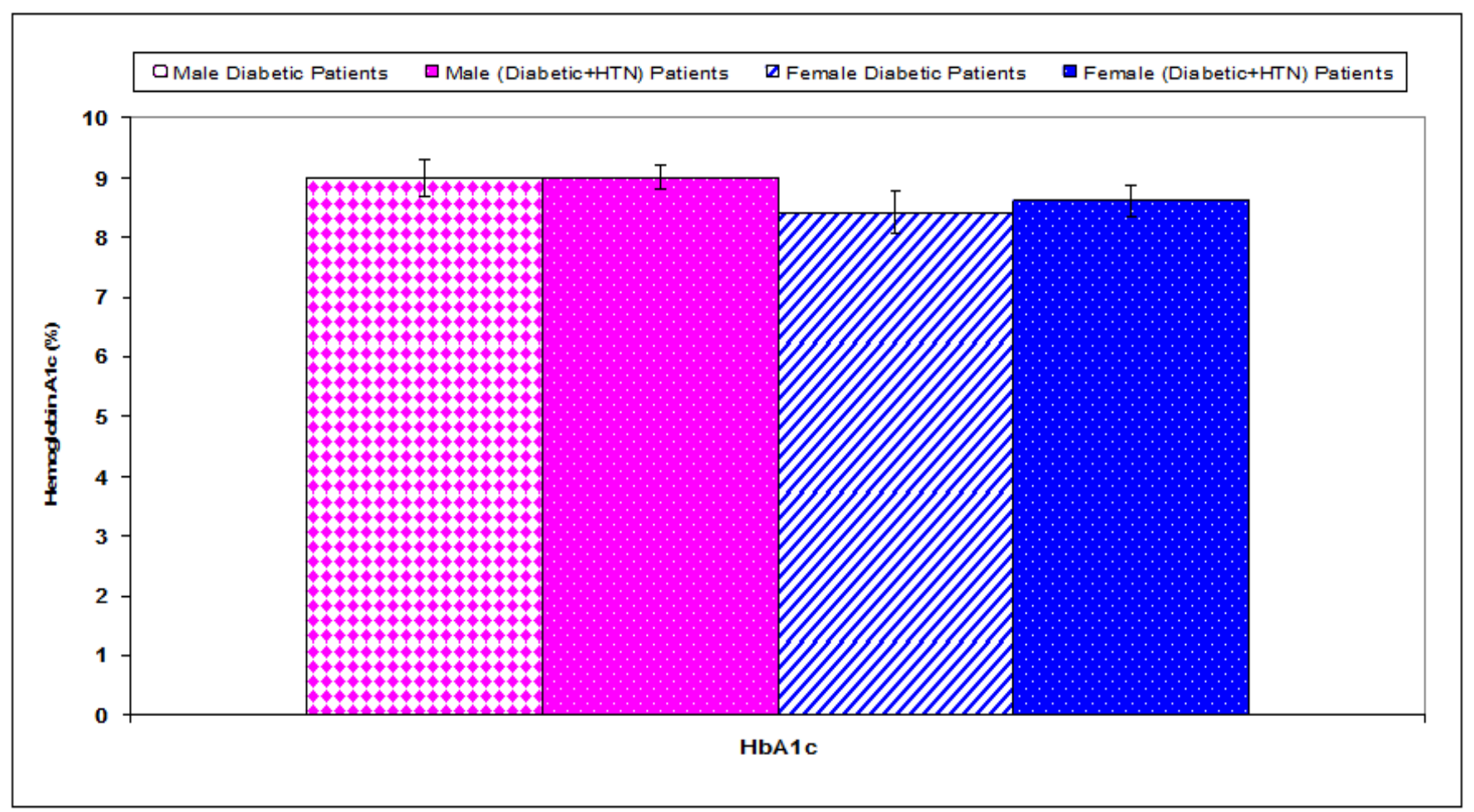

Figure 13 Comparison of Hemoglobin Alc between diabetic patients and diabetic + HTN patients. 


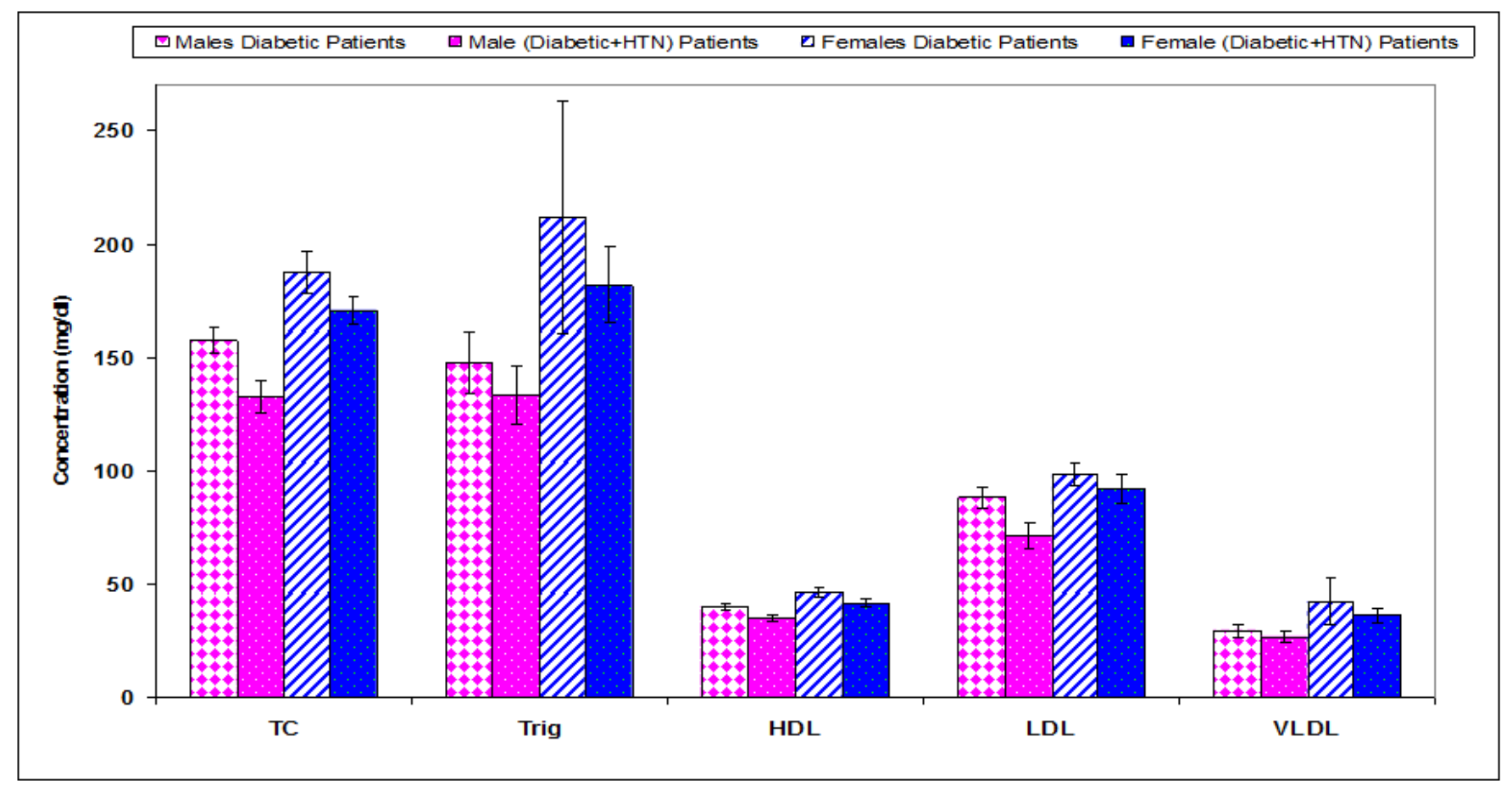

Figure 14 Comparison of serum lipid parameters concentrations between diabetic patients and diabetic+HTN patients.

\section{Discussion}

In diabetic patients, hyperglycemia leads to heart diseases and when failing to control diabetes, it can give rise to many complications. ${ }^{5,26}$ The associated obesity, hyperglycemia, and insulin changes highly accelerate the progression to atherosclerosis. ${ }^{15,27,28}$ In the present study, the mean ages of males diabetic, and females patients were $(57.70 \pm 2.30)$ and $(53.00 \pm 1.59)$ years, diabetic + HTN males and females patients were $(58.10 \pm 2.40)$, and $(56.60 \pm 1.68)$, these results are similar with results of Al Salhen and Mahmoud, ${ }^{5}$ who found that the mean ages of diabetic patients in El-Beida, Libya were $(56.10 \pm 7.82)$ years $(M e a n \pm S D)$. In the present study, the subjects of age more than 50 years were $75 \%$ in males diabetic patients, and $71.7 \%$ in females diabetic patients, $85 \%$ in males diabetic + HTN patients and $78.3 \%$ in females diabetic+HTN patients. Al Salhen and Mahmoud, ${ }^{5}$ and Umpierrez et al., ${ }^{29}$ were mentioned that T2DM usually develops after age 40 years. The worldwide obesity has doubled since 1980. In 2008 , more than 1.4 billion adults were either obese or overweight, about 300 million women were affected. ${ }^{30,31}$ It is estimated that there is seven times greater risk of an individual being diabetic than a healthy one, with a threefold rise in menace for overweight people. ${ }^{31,32}$ The present study showed that the subjects of BMI more than $25 \mathrm{Kg} / \mathrm{m}^{2}$ were $83.3 \%$ in males and females diabetic patients, $80 \%$ in males diabetic + HTN patients and $91.7 \%$ in females diabetic + HTN patients. Our results run parallel to the study of Vinciguerra et al., ${ }^{33}$ who suggested that the threat of T2DM was observed in those individuals who have BMI greater than 40 as compared to those who have lower BMI. The relationship between obesity and T2DM is complicated by the effects of several modifying factors which include distribution of body fat, duration of obesity, diet, physical activity, and genetics/ ethnicity. ${ }^{31,33,34}$ Also, Choudhury et al., ${ }^{35}$ reported that age and BMI were showed a significant increased in hypertensive patients as compared with normotensives. Also, the authors recorded that about $80 \%$ of hypertensive persons have comorbidities such as obesity, glucose intolerance, abnormalities in lipid metabolism. Genetic factors related to the distribution of some blood groups may play a role in the development of both elevated blood pressure and type 2 diabetes.

The fat cells secrete pro-inflammatory chemicals, which makes the body cells less sensitive to insulin. These chemicals also deteriorate the function of responsive cells and their capacity to respond to insulin. ${ }^{36}$ Recent studies have identified "links" between obesity and type 2 diabetes involving pro-inflammatory cytokines (tumor necrosis factor and interleukin-6), insulin resistance, deranged fatty acid metabolism, and cellular processes such as mitochondrial dysfunction and endoplasmic reticulum stress. More importantly, indexes of obesity play an unusual role in screening T2DM and determining highrisk individuals. ${ }^{31,37}$ Elevation in DBP was positively associated with age and BMI. The likelihood of diabetes increased with HTN, age, and BMI. ${ }^{38}$ The current study showed that a significantly increased in HbAlc and serum glucose in diabetic patients this result agrees with findings obtained by Satti et al., ${ }^{4}$ and Sacks, ${ }^{39}$ who revealed that a positive correlation between serum blood glucose concentration and increased $\mathrm{HbAlc}$. The present study showed that serum total cholesterol and LDL concentration was a significant $(\mathrm{P}<0.01)$ increase in males and females diabetic compared with controls. But, HDL concentration was a significant $(\mathrm{P}<0.01)$ increase in females diabetic compared with control females. Serum LDL levels were abnormal in $46.7 \%, 41.7 \%, 33.3 \%, 20 \%$ of diabetic plus hypertension females, diabetic females, diabetic males, and diabetic plus hypertension males respectively. Serum HDL levels were abnormal in $65 \%, 55 \%$, $51 \%$, and $36.7 \%$ of diabetic plus hypertension males and females, diabetic males, and diabetic females, respectively. Serum cholesterol 
levels were abnormal in $30 \%, 23.3 \%, 8.3 \%$, and $5 \%$ of diabetic plus hypertension females, diabetic females, diabetic males, and diabetic plus hypertension males respectively. Also, serum triglycerides were abnormal in $55 \%, 41 \%, 36.7 \%$, and $35 \%$ of diabetic plus hypertension females, diabetic males and females, and diabetic plus hypertension males, respectively. These results are in concordant with the study of Alam et al., ${ }^{40}$ had shown $33 \%$ of serum cholesterol levels were abnormal in diabetic. For this reason, if diabetes subjects are longtime suffering from hyperlipidemia then cardiovascular risk factors and macrovascular complications increase to an alarming level. Basit et al. ${ }^{41}$ demonstrated an association with hypertension and hypertriglyceridemia with poor glycemic control.

The present study showed that serum total cholesterol, triglycerides, LDL, and VLDL concentration were significantly $(P<0.01)$ increased in females diabetic + HTN compared with control females. However, there were non-significant changes recorded in serum total cholesterol, triglycerides, LDL, and VLDL concentration in male diabetic patients + HTN compared to controls. HDL concentration was significantly $(P<0.01)$ decreased in males diabetic compared with control females. These results are similar to the findings of some other studies, ${ }^{35,42,43}$ Choudhury et al., ${ }^{35}$ found that the serum total cholesterol, triglycerides, and LDL concentrations were higher while high- density lipoprotein concentrations were lower in hypertensive patients compared to normotensives, which was statistically significant. Also, Islam and Majumder, ${ }^{44}$ recorded that a high serum TG, TC, and LDL among Bangladesh hypertensive patients when compared with healthy normotensive controls. Dysfunctional adipose tissue is less sensitive to insulin and has reduced hormone-sensitive lipase activity compared that of normal adipose tissue. As a result, there is an increased breakdown of intracellular triglycerides and increased release of free fatty acids into circulation, leading to fatty infiltration in the liver, muscles and possibly pancreatic $\beta$-cells. Ultimately, this contributes to and may exacerbate, insulin resistance in the liver and muscle. After long term exposure to free fatty acids, the function of the pancreatic $\beta$-cells may also be compromised, leading to increased predisposition to T2DM. Increased hepatic free fatty acids contribute to the increased hepatic synthesis of TG, which in turn results in elevated concentrations of very LDL (VLDL) particles. As a consequence, the characteristic hypertriglyceridemia and possible fatty liver emerge, a common finding in patients with insulin resistance. Afterward, various lipases contribute to the remodeling of VLDL to small, dense LDL particles. Also, cholesteryl ester transfer protein (CETP) exchanges TG from VLDL to cholesterol found in HDL and LDL, leading to cholesterol-rich atherogenic VLDL particles. HDL particles that undergo these modifications are cleared more readily by the kidney, resulting in lower HDL-C levels. The more TG-rich LDL particles undergo metabolism by lipases, again resulting in small, dense LDL particles that exhibit increased atherogenicity. ${ }^{11}$

\section{Conclusion}

It can be concluded that the results showed significant changes in most of the parameters in diabetic patients with and without hypertension compared to healthy subjects. Most of these changes were more pronounced in diabetics with hypertension patients than diabetics patients only. Therefore, lipid profiling of all patients with diabetic patients with and without hypertension should be a routine test in periodic clinical practice because early diagnosis may play a role in slowing the progression of cardiovascular diseases and other harmful consequences of diabetes and hypertension. Thus, management and treatment of the disease should be executed very soon, even before the onset of symptoms of this disease. All patients with T2DM patients with and without hypertension must be started on primary prevention by health education, aggressive lifestyle changes, such as weight reduction and physical exercise to reduce the risk of coronary heart disease and atherosclerosis. Further studies are essential in a larger population and in other ethnic groups to confirm these results. Health education should be implemented targeted to diabetic and hypertension patients and through all media and channels for spreading the needed information, which will help significantly in controlling of complications diabetes and hypertension.

\section{Acknowledgment}

None.

\section{Conflicts of interest}

The authors declare that there are no conflicts of interest.

\section{Funding}

None.

\section{References}

1 Sicree R, Shaw J, Zimmet P. The global burden, diabetes and impaired glucose tolerance. Diabetes atlas, international diabetes federation, 4th edition, international diabetes federation, Belgium. 2006.

2 Kunde PB, Zade DC. Effect of intervention on the behavioural risk factors of type 2 diabetes: A study among high risk adults in a tribal area of western Maharashtra. Inter J Rec Tren Sci Technol. 2014;12(2):307-310.

3 Ahmida M, Gatish Z, Al-Badry S, et al. Dyslipidemia in type II diabetes mellitus patients in Benghazi, Libya. Inter J Biomed Advan Res. 2015;6(10):749-753.

4 Satti S, Gurashi RA, Fadul O. Evaluation of hyponatremia among type 2 diabetes patients in Sudan. J Med Biol Sci Res. 2017;3(1):5-8.

5 Al Salhen KS, Mahmoud AY. Determinants of abnormal kidney function tests in diabetes patient type 2 in Libya. Inter $J$ Sci Stud. 2016;4(6):99-103.

6 Beshyah SA. Non-communicable diseases and diabetes care guidelines: Epidemiology and call for collective action, February, 6th 2010. Dat Elmad Conference Hall Complex, Tripoli, Libya. Conf Report. Ibnosina J Med Biomed Sci. 2010;2(3):142-148.

7 World Health Organization (WHO). Definition, diagnosis, and classification of diabetes mellitus and its complications. Part 1: diagnosis and classification of diabetes mellitus. Report of a WHO consultation. 1999.

8 Balagopal P, Kamalamma N, Misra R, et al. A community based diabetes prevention and management education program in a rural village in India. Diabetes Care. 2008;31(6):1097-1104.

9 Kudchodkar BJ, Lee MJ, Lee SM, et al. Effect of dietary protein on cholesterol homeostasis in diabetic rats. J Lipid Res. 1988;29(10):12721287.

10 Maduka IC, Egwu MC. The relationship between alcoholism and cardiac biomarkers in non insulin dependent diabetics. Pharm Chem J. 2017:4(1):60-66. 
11 Kalofoutis C, Piperi C, Kalofoutis A, et al. Type II diabetes mellitus and cardiovascular risk factors: Current therapeutic approaches. Exp Clin Cardiol. 2007;12(1):17-28.

12 Barrett-Connor EL, Cohn BA, Wingard DL, et al. Why is diabetes mellitus a stronger risk factor for fatal ischemic heart disease in women than in men? The Rancho Bernardo Study. JAMA. 1991;265(5):627631

13 Albarracin MLG. Hypertension and diabetes: A latent problem in Colombia. Inter J Card Pulmon Rehabil. 2018;2018(1):1-6.

14 Preis SR, Pencina MJ, Hwang SJ, et al. Trends in cardiovascular disease risk factors in individuals with and without diabetes mellitus in the Framingham Heart Study. Circulation. 2009;120(3):212-220.

15 Arauz-Pacheco C, Parrott MA, Raskin P, et al. American diabetes association. Treatment of hypertension in adults with diabetes. Diabetes Care. 2003;26(Suppl 1):S80-S82.

16 de Ferranti SD, de Boer IH, Fonseca V, et al. Type 1 diabetes mellitus and cardiovascular disease: a scientific statement from the American heart association and American diabetes association. Circulation. 2014;130(13):1110-1130.

17 Fox CS, Golden SH, Anderson C, et al. Update on prevention of cardiovascular disease in adults with type 2 diabetes mellitus in ligh of recent evidence: a scientific statement from the American Heart Association and the American Diabetes Association. Circulation. 2015;132(8):691-718

18 de Boer IH, Bangalore S, Beneto A, et al. Diabetes and hypertension: a position statement by the American diabetes association. Diabetes care. 2017;40(9):1273-1284.)

19 Castelli WP. Epidemiology of coronary heart disease: the Framingham study. Am J Med. 1984;76(2A):4-12.

20 Kaur M, Gill K, Bassi R, et al. Association of ABO and Rh blood groups with hypertension. Pak J Physiol. 2016;12(2):11-14.

21 Morgado E, Neves PL. Hypertension and chronic kidney disease: Cause and consequence-therapeutic considerations, antihypertensive drugs, Babaei H (Edition), InTech. 2012.

22 Richmond W. Preparation and properties of a cholesterol oxidase from Nocradia sp. and its application to the enzymatic assay to total cholesterol in serum. Clin Chem. 1973;19(12):1350-1356.

23 Carr TP, Andressen CJ, Rudel LL. Enzymatic determination of triglyceride, free cholesterol and total cholesterol in tissue lipid extracts. Clin Biochem. 1993;26(1):39-42.

24 Assmann G, Jabs HU, Kohnert U, et al. LDL-cholesterol determination in blood serum following precipitation of LDL with polyvinylsulfate. Clin Chim Acta. 1984;140(1):77-83

25 Burstein M, Scholnick HR, Morfin R. Rapid method for the isolation of lipoproteins from human serum by precipitation with polyanions. $J$ Lipid Res. 1970;11(6):583-595.

26 Hofso D, Jenssen T, Bollerslev J, et al. Anthropometric characteristics and type 2 diabetes in extremely obese caucasian subjects: A crosssectional study. Diabetes Res Clin Pract. 2009;86(1):e9-e11.
27 Nesto RW. Correlation between cardiovascular disease and diabetes mellitus: current concepts. Amer J Med. 2004;116(Supp 5A):11S-22S.

28 Bornfeldt KE, Tabas I. Insulin resistance, hyperglycemia, and atherosclerosis. Cell Metab. 2011;14(5):575-585.

29 Umpierrez GE, Smiley D, Kitabchi AE. Narrative review: Ketosisprone type 2 diabetes mellitus. Ann Intern Med. 2006;144(5):350-357.

30 World Health Organization (WHO). Obesity and overweight. Fact Sheet No.31. 2013

31 Kaur H. Diabesity and hypertension. Galore Inter J Health Sci Res. 2016;1(1):1-9.

32 Abdullah A, Stoelwinder J, Shortreed S, et al. The duration of obesity and the risk of type 2 diabetes. Pub Health Nutr. 2011;14(1):119-126.

33 Vinciguerra F, Baratta R, Farina MG, et al. Very severely obese patients have a high prevalence of type 2 diabetes mellitus and cardiovascular disease. Acta Diabetol. 2013;50(3):443-449.

34 Singla R, Murthy M, Singla S, et al. Friendly fat theory-explaining the paradox of diabetes and obesity. Eur Endocrinol. 2019;15(1):25-28.

35 Choudhury KN, Mainuddin AK, Wahiduzzaman M, et al. Serum lipid profile and its association with hypertension in Bangladesh. Vasc Health Risk Manag. 2014;10:327-332.

36 Despres JP. Body fat distribution and risk of cardiovascular disease: an update. Circulation. 2012;126(10):1301-1313.

37 Eckel RH, Kahn SE, Ferrannini E, et al. Obesity and type 2 diabetes What can be unified and what needs to be individualized?. J Clin Endocrinol Metab. 2011;96(6):1654-1663

38 Nemesure B, Wu S, Hennis A, et al. Hypertension, type 2 diabetes, and blood groups in a population of African ancestry. Ethn Dis. 2006;16(4):822-829.

39 Sacks DB. Correlation between Hemoglobin A1c (HbAlc) and average blood glucose: Can HbAlc be reported as estimated blood glucose concentration?.J Diabetes Sci Technol. 2007;1(6):801-803.

40 Alam J, Chandra SM, Mokarrama MN, et al. A comparative analysis of biochemical and hematological parameters in diabetic and nondiabetic adults. Advanced Medical Sciences: An International Journal (AMS). 2015;2(1):1-9.

41 Basit A, Hydrie MZ, Hakeem R, et al. Glycemic control, hypertension and chronic complications in type 2 diabetic subjects attending a tertiary care center. J Ayub Med Coll Abottabad. 2005;17(2):63-68.

42 Saha MS, Sana NK, Shaha RK. Serum lipid profile of hypertensive patients in the northern region of Bangladesh. J Bio Sci. 2006;14:9398

43 Pooja, Mittal Y, Mathur A. Evaluation of lipid profile of North Indian hypertensive subjects. Asian J Biomed Pharm Sci. 2013:3(18):38-41

44 Islam AK, Majumder AA. Hypertension in Bangladesh: a review. Indian Heart J. 2012:64(3):319-323. 